\title{
Molecular stratifications, biomarker candidates and new therapeutic options in current medulloblastoma treatment approaches
}

\author{
Otília Menyhárt ${ }^{1,2} \cdot$ Balázs Győrffy ${ }^{1,2}$
}

Published online: 22 January 2020

(C) The Author(s) 2020

\begin{abstract}
Medulloblastoma (MB) is the most common malignant childhood tumor of the brain. Multimodal treatment consisting of surgery, radiation therapy, and chemotherapy reduced cumulative incidence of late mortality but increased the incidence of subsequent neoplasms and severe, incapacitating chronic health conditions. Present treatment strategies fail to recognize heterogeneity within patients despite wide divergence in individual responses. The persistent mortality rates and serious side effects of non-targeted cytotoxic therapies indicate a need for more refined therapeutic approaches. Advanced genomic research has led to the accumulation of an enormous amount of genetic information and resulted in a consensus distinguishing four molecular subgroups, WNTactivated, SHH-activated, and Group 3 and 4 medulloblastomas. These have distinct origin, demographics, molecular alterations, and clinical outcomes. Although subgroup affiliation does not predict response to therapy, new subgroup-specific markers of prognosis can enable a more layered risk stratification with additional subtypes within each primary subgroup. Here, we summarize subgroup-specific genetic alterations and their utility in current treatment strategies. The transition toward molecularly targeted interventions for newly diagnosed MBs remains slow, and prospective trials are needed to confirm stratifications based on molecular alterations. At the same time, numerous studies focus at fine-tuning the intensity of invasive radio- and chemotherapies to reduce intervention-related long-term morbidity. There are an increasing number of immunotherapy-based treatment strategies including immune checkpoint-inhibitors, oncolytic viruses, CAR-T therapy, and NK cells in recurrent and refractory MBs. Although most trials are in early phase, there is hope for therapeutic breakthroughs for advanced MBs within the next decade.
\end{abstract}

Keywords Prognostic biomarker · Risk stratification · Clinical trial $\cdot$ WNT $\cdot$ SHH $\cdot$ Group $3 \cdot$ Group $4 \cdot$ Immunotherapy

Key messages

- Contemporary treatment strategies fail to consider heterogeneity among medulloblastoma (MB) patients.

- Arising subgroup-specific markers of prognosis lead to a layered risk stratification of MBs, but prospective trials are needed to confirm their utility.

- Most studies on newly diagnosed patients focus on fine-tuning the intensity of current radio- and chemotherapies.

- More targeted and immunotherapy-based treatment strategies are available in recurrent and refractory MBs.

- The transition toward molecularly guided interventions for newly diagnosed MBs remains slow.

Balázs Győrffy

gyorffy.balazs@ttk.mta.hu

1 2nd Department of Pediatrics and Department of Bioinformatics, Semmelweis University, Budapest, Hungary

2 Research Centre for Natural Sciences, Cancer Biomarker Research Group, Institute of Enzymology, Magyar tudósok körútja 2, Budapest H-1117, Hungary

\section{Introduction}

Medulloblastoma (MB) is the most common malignant childhood tumor of the brain, accounting for $\sim 20 \%$ of all CNS tumors among children [1]. Current multimodal treatment consisting of surgery, radiation therapy, and chemotherapy allows 60-80\% long-term survival [2]. According to a report from the Childhood Cancer Survivor Study comparing longterm mortality and morbidity data, cumulative incidence of all-cause late mortality became significantly lower for MB patients diagnosed in the 1990s compared to the 1970s [3]. Still, more than one-third of patients die within 5 years after diagnosis [1], and the median survival of relapsed/refractory MB is less than 1 year [4]. Each treatment component is responsible for late complications leading to severe, debilitating chronic health conditions [3]. Late mortality remains a significant problem, largely attributable to disease recurrence and secondary malignancies [5]. The current clinical and pathological feature-based risk stratification fails to consider 
heterogeneity within standard- and high-risk patients. The wide disparities among patient outcomes, the deteriorating quality of life expectations for survivors, and the failure of aggressive, high intensity multimodal therapies to extend life expectancy of patients with recurrent disease illuminate the need for new, more effective treatment approaches.

Integration of molecular data provided by advanced genomics started an exciting refinement of MB classifications [6]: the current consensus agrees upon four distinct molecular subgroups, wingless-activated (WNT-MB), sonic-hedgehogactivated (SHH-MB), and Group 3 and Group 4 MBs [7], each characterized by distinct variety of genetic alterations, transcriptional/methylation profiles, and clinical outcomes $[2,8-10]$. Subgroup identity is linked with markedly different survival, although subgroup affiliation does not correlate with response to therapy [11]. Within each primary subgroup, additional molecular markers started to emerge, leading to more refined risk stratifications [2]. Ongoing trials explore personalized treatment strategies for patients harboring specific genetic aberrations.

In this review, we summarize treatment approaches, outline the evolving landscape of molecular classifications, and discuss markers with prognostic relevance. Our main focus is the ongoing transition toward molecular-based risk-adapted strategies in the clinic. We review currently recruiting clinical trials available for both newly diagnosed and recurrent/refractory MB patients. A decent tendency among current trials is the increasing number of targeted and immunotherapy-based approaches, although up till now exclusively for patients with recurrent/refractory MBs.

\subsection{Clinical classification and current treatment protocols}

Current treatment approaches consider two main factors for the selection of postoperative therapy: risk of treatment toxicity and risk of recurrence. Risk of treatment toxicity is especially significant for infants and children younger than 3 years of age. Risk of recurrence is considered to be high in case of disseminated or metastatic disease or suboptimal resection, with a tumor residue $\geq 1.5 \mathrm{~cm}^{2}$. Certain histologic subtypes, such as anaplastic and large cell tumors, have also been associated with poor outcome [12]. Three treatment cohorts can be separated based on these criteria: children older than 3 years of age with average-risk disease, children older than 3 years of age with high-risk disease, and infants and children younger than 3 years of age.

\subsubsection{Surgical intervention}

Surgical goal is maximal safe resection that alleviates increased intracranial pressure and removes as much tumor tissue as possible without causing adverse neurological sequelae, such as cranial nerve deficits or persistent ataxia. Posterior fossa syndrome (cerebellar mutism) still occurs in about one-quarter of patients with MB resection. Development of modern imaging and surgical techniques prompted gross total or near-total resection in most patients [13]. Meanwhile, the magnitude of the extent of resection may not be as significant as earlier thought to be: an inconclusive retrospective systematic review on the extent of resection and disease outcome warrants further evaluation [14]. Prognostic benefits may also be attenuated by molecular subgroups: gross total resection in Group $4 \mathrm{MB}$ patients conferred progressionfree survival benefit compared to subtotal resection, especially in the presence of disease dissemination, while the extent of resection was not linked to overall survival (OS) [13].

\subsubsection{Radiation therapy (RT)}

Following surgery patients are treated with external beam irradiation to the craniospinal axis with an additional boost to the tumor site, with varying radiation doses across risk groups. Most recurrences (50-70\%) are local; therefore treatment is limited to the tumor bed compared to the entire posterior fossa which spares critical brain structures [15]. RT is usually initiated 30 days after surgery, since delayed RT administration is associated with lower survival $[8,16]$. At the same time, a more recent study identified decreased 5-year OS in patients with RT initiated within 3 weeks after surgery, indicating ample time for healing is also paramount [17].

Patients with average-risk disease are treated with $23.4 \mathrm{~Gy}$ craniospinal irradiation (CSI) to the entire brain and spine, with posterior fossa boost for a total dose of 54-55.8 Gy [18-22]. In contrast, high-risk patients receive 36-39.6 Gy CSI with an additional boost to the tumor site, for a total dose of 54-55.8 Gy [21]. Such RT doses are associated with neurocognitive impairment, affecting younger children more negatively [23]. However, reduced-dose neuraxis photon RT results in increased frequency of relapse and decreased survival [24]. In the phase III Children's Oncology Group ACNS0331 trial, 5.4 Gy reduction in the CSI dose in children between 3 and 7 years of age produced inferior survival compared to standard-dose RT [25]. Deferral of postoperative RT even in the modern era of chemotherapy is associated with poorer OS and is therefore not recommended for children older than 3 years of age [26].

Newer techniques, such as proton radiation therapy and intensity-modulated RT utilized for the posterior fossa boost and spine RT, limit irradiation of the normal tissues with acceptable toxicity and survival similar to conventional RT [27]. Reduced normal tissue dose also relieves post-radiation ototoxicity, leading to preserved hearing and improved quality of life $[28,29]$. Nevertheless, additional studies are needed to determine if proton beam RT provides clinically meaningful 
long-term cognitive sparing compared to photon beam RT protocols [30].

\subsubsection{Chemotherapy}

Following postsurgical RT, chemotherapy became accepted as a standard treatment as it improves survival and reduces RTrelated adverse effects, especially in younger children. Numerous risk-adapted multimodal treatment protocols have been tested in clinical trials. A randomized, multicenter trial (HIT'91) compared the long-term effects of a neoadjuvant ("sandwich") chemotherapy (incorporating ifosfamide, etoposide, high-dose methotrexate, cisplatin, and cytarabine, followed by CSI and maintenance chemotherapy) versus "maintenance" chemotherapy after radiation (consisting of vincristine complementary to RT and eight cycles with CCNU, vincristine and cisplatin 6 weeks after RT), adapted from the "Packer protocol." The "maintenance" regimen resulted in significantly higher 10-year OS compared to the "sandwich" approach among patients with M0 (91\% vs. $62 \%)$ or M1 (70\% vs. 34\%) disease [31, 32].

The phase III Children's Oncology Group (COG) study adopted a weekly vincristine treatment during RT, followed by eight cycles of chemotherapy including vincristine and cisplatin plus CCNU, or vincristine and cisplatin plus cyclophosphamide. The strategy leads to $76 \%$ and $81 \%$ 10-year event-free and overall survival, respectively, in average-risk patients, with no differences in efficacy between the two chemotherapy regimens $[22,33]$, producing at least as good outcome as previous, more intensive treatment protocols.

The current treatment approach includes risk-adapted RT and four cycles of cyclophosphamide-based, dose-intensive chemotherapy (incorporating cisplatin, vincristine, and cyclophosphamide), followed by stem cell or bone marrow rescue. This regimen produced 85\% 5-year survival (95\% CI 75-94) in the average-risk MB population and 70\% 5-year survival (95\% 54-84) in the high-risk population [21]. Histological subtype also correlated with 5-year event-free survival and was lowest (57\%) for large cell anaplastic tumors [21].

Additional ongoing clinical trials test the feasibility of alternative treatment regimes in newly diagnosed MBs. The recruiting SIOP PNET $5 \mathrm{MB}$ phase II/III trial (NCT02066220) evaluates the outcome in patients with nonWNT "standard-risk" biological profiles, defined by nuclear beta-catenin immune-negativity, after concurrent carboplatin and radiotherapy, followed by eight cycles of maintenance chemotherapy (Table 1).

Up to $30 \%$ of $\mathrm{MB}$ patients are diagnosed with a metastatic disease [34]. Despite high intensity RT and chemotherapy, the risk of recurrence and death remains elevated. A Children's Oncology Group Phase I/II trial for metastatic patients administered 36 Gy CSI with boosts to the sites of disease, complemented with carboplatin along with vincristine during radiation, followed by six maintenance cycles of cyclophosphamide and vincristine with or without cisplatin. The regimen without cisplatin resulted in $82 \%$ 5-year survival, compared to $68 \%$ in the cisplatin arm [35]. Another approach for high-risk patients included a reduced-dose CSI (23.4 to 30.6 Gy) complemented with tandem high-dose chemotherapy ( 2 cycles pre- and 4 cycles post RT) and autologous stem cell transplantation. The treatment resulted in 70\% 5-year event-free and $74 \%$ overall survival rates [36], although sample size was low and longer follow-up is needed to evaluate the potential long-term risks of high-dose chemotherapy, especially as chemotherapy may aggravate neurological adverse effects [37]. The HIT'2000 trial for patients with gross leptomeningeal dissemination (M2/3) adapted an intensified "sandwich"-regimen, including strengthened induction chemotherapy (comprising two cycles of intravenous cyclophosphamide, vincristine, methotrexate, carboplatin, etoposide, and concomitant intraventricular methotrexate), hyperfractionated CSI, and four cycles of maintenance chemotherapy (consisting of cisplatin, $\mathrm{CCNU}$, and vincristine). The trial resulted in superior survival rates compared to the preceding HIT'91 trial: the 5-year OS reached 74\% (95\% CI 66-82\%), with histology and nonresponse to the first chemotherapy cycle as independent risk factors [38]. Survival was associated with molecular subgroup identity and the presence of $M Y C C / M Y C N$ amplifications, suggesting that these may be useful biomarkers in future treatment stratifications [38].

Infants and children under the age of 3 are preferably treated by surgery and chemotherapy alone due to high-risk of radiation-induced morbidity [39]. The CCG-99703 protocol consists of high-dose chemotherapy (vincristine, cyclophosphamide, etoposide, and cisplatin) followed by autologous hematopoietic cell rescue, while the HIT-SKK'92 protocol endorses systemic chemotherapy and intraventricular therapy (intravenous and intraventricular methotrexate, vincristine, cyclophosphamide, and carboplatin) [40, 41]. HIT-SKK'92 led to better outcomes in patients with gross total resection and without metastases compared to patients with residual or metastatic disease [41-43]. Delay of radiation therapy may be particularly favorable in young children with desmoplastic/ extensive nodular histology [44], and sequential high-dose chemotherapy following the CCG-99703 protocol produced an excellent outcome for SHH-MB patients with classical histology [39].

Novel protocols are being evaluated to circumvent the debilitating complications linked to radiation therapy by extending the age range of young patients (Table 1). A phase II (NCT02025881) open-label, non-randomized trial focuses on children under the age of 5 with newly diagnosed highrisk MBs and investigates the efficacy of a sequential highdose chemotherapy without radiotherapy with stem cell support. Risk assignment is based on histology (large cell/ anaplastic (LCA) or other unfavorable), dissemination, and 


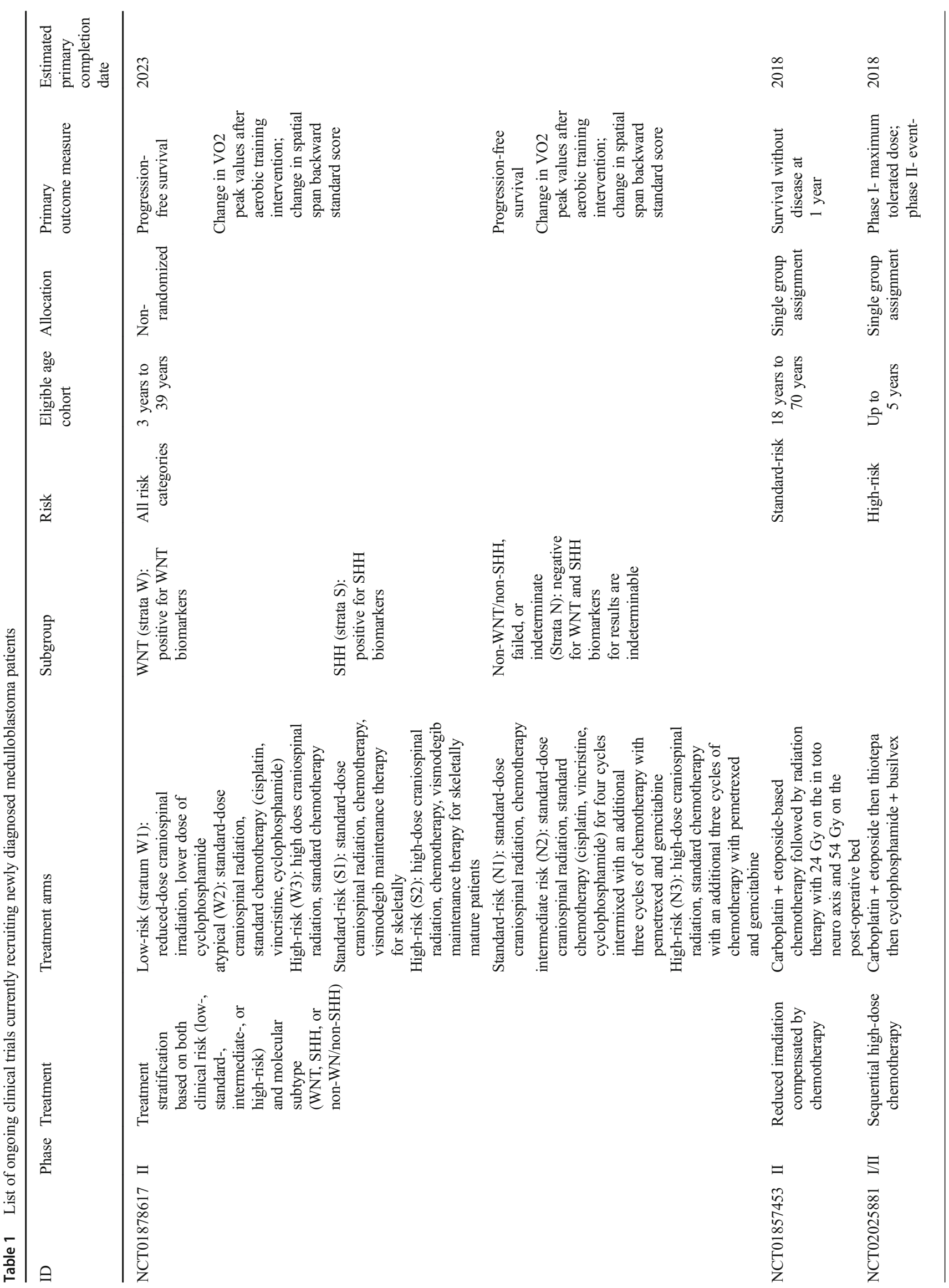




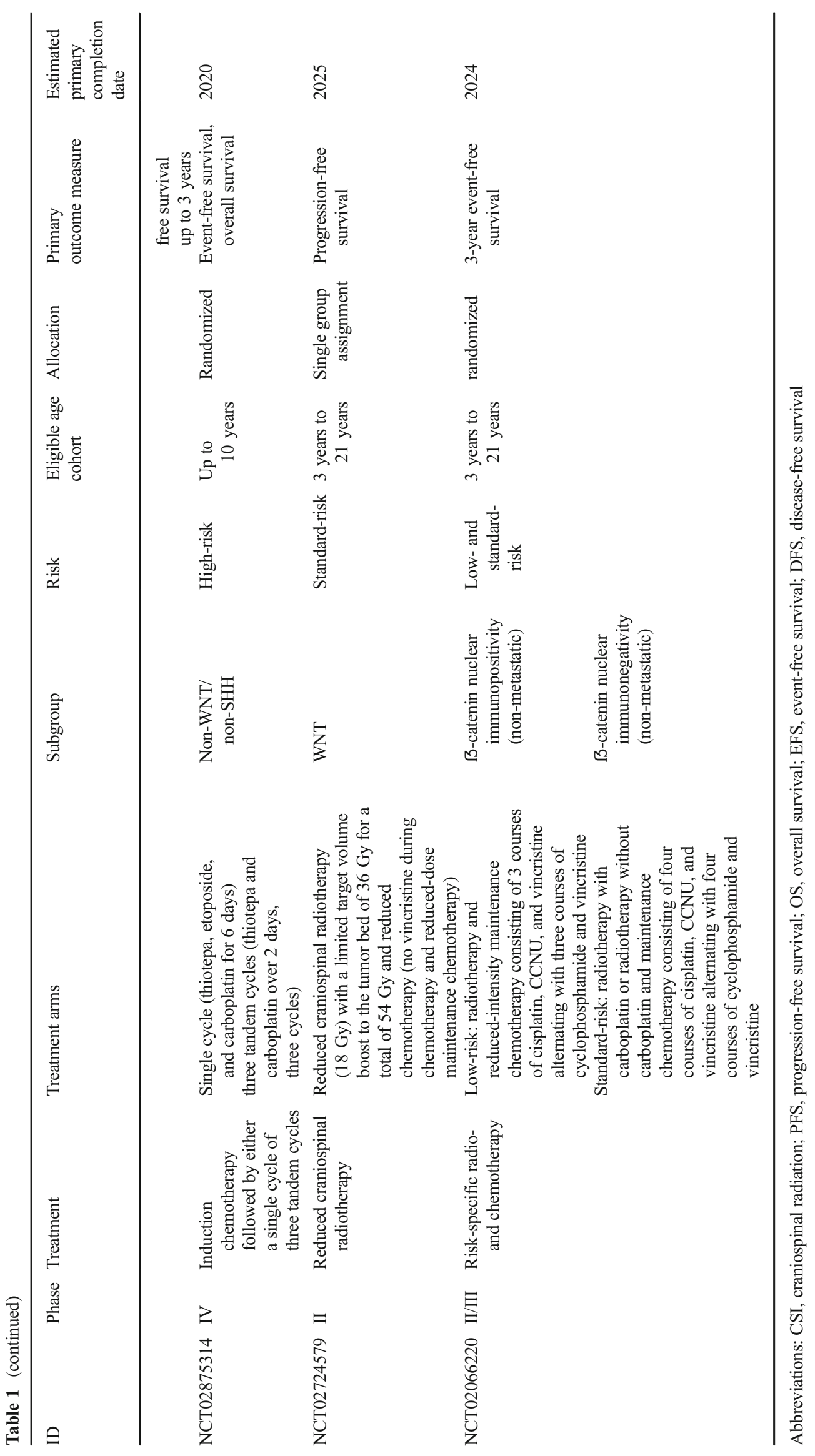


the presence of $M Y C$ and $M Y C N$ amplifications, and the chemotherapy regimen includes carboplatin + etoposide, then thiotepa, then cyclophosphamide, and busilvex. The study includes a phase I dose-finding part to determine the dose of cyclophosphamide that can be given in combination with busilvex. The phase IV HeadStart4 trial (NCT02875314) focuses on newly diagnosed high-risk children (up to 10 years of age) mainly consisting of non-WNT/non-SHH-MBs, and evaluates the efficacy of a high intensity induction therapy (including vincristine, cisplatin, cyclophosphamide, etoposide and high-dose methotrexate) followed by either a single cycle (carboplatin, thiotepa, etoposide) or three tandem cycles (carboplatin, thiotepa) of consolidation marrow-ablative chemotherapy with autologous hematopoietic progenitor cell rescue. Risk assessment is based on clinical features such as age (all MBs under the age of 6), histology, and stage (high disease stage with classic or LCA histology between the ages of 6 and 10).

In adults, MBs are rare, accounting for $<1 \%$ of all CNStumors, and most adult patients belong to the standard clinical risk group. Due to the relatively low incidence of adult MBs, there are no randomized clinical trials upon which to base treatment recommendations. After maximal safe resection, adult patients are treated with normofractionated CSI of 3036 Gy followed by a tumor bed boost to $54-55.8$ Gy and occasional chemotherapy, particularly for high-risk disease, with unknown outcomes $[45,46]$. However, such conventional radiation therapy is associated with progressive neurotoxicity, leading to the degradation of the quality of life. An ongoing phase II trial (NCT01857453) investigates the effects of reduced irradiation compensated by carboplatin- and etoposide-based chemotherapy in newly diagnosed, clinically standard-risk adult patients (ages 18 to 70) (Table 1). The study also aims to assess the relevance of prognostic biomarkers used in the pediatric population for older patients.

\subsection{Molecular classifications and subgroup-specific molecular alterations}

Given the wide variety of responses to standard of care treatment approaches, the current challenge is to identify patients for whom reduced intervention may boost cure rates while alleviating long-term adverse sequelae or alternatively to identify those who are incurable with paradigm treatments and whom participation in clinical trials would be recommended. Thus, recognizing molecular subgroups provides an opportunity to personalize therapy and avoid over- or under-treatment.

An early genomics study investigating gene expressionbased clustering partitioned MB into separate subgroups, each with different histologic, molecular and clinical profiles [47], and the results were corroborated by subsequent analyses with extended sample sizes [12, 48-50]. Four main molecular subgroups were defined [7], and the new subclassification was integrated into the revised WHO system published in 2016
[6]. WNT- and SHH-activated MBs are clearly separable entities from the other subgroups, while no dominant signaling pathway alterations were identified in Group 3 and Group 4 MBs. The latter ones are more related to each other than to the other MBs and therefore appear as non-WNT/non-SHH in the revised WHO classification [6]. The subgroup assignment is still provisory and flexible to further alterations, as Group 3 and 4 MBs encompass a heterogeneous population at both the molecular and clinical levels $[13,49,51]$. Subgroup identity is highly prognostic with markedly different outcomes across the four principal subgroups [11], although survival also strongly depends on histology, presence of metastases, and molecular abnormalities [7, 12, 52, 53].

\subsubsection{WNT-activated MBs}

WNT-MBs are the least common, accounting for about $10 \%$ of all MB patients (Fig. 1). More than $90 \%$ of tumors display classic histology, and metastasis is rare with $\sim 9 \%$ frequency at diagnosis $[49,52]$. WNT-MBs are typically absent in infants and are found among older children (median age of 1012 years), with almost equal ratio of males and females [7, 54]. Prognosis under 16 years of age is usually excellent, with more than 90\% 5-year event-free survival [55]. The first European prospective study of MB biomarkers investigating non-metastatic, clinically defined standard-risk tumor samples validated the good prognosis associated with WNT-activated MBs. Higher frequency of relapses were observed in patients older than 16 years of age at diagnosis and in those with delayed radiotherapy, indicating that radiation is an important treatment component [56]. Outcome in adult patients (over 16 years of age) requires further investigations [57, 58]. A recent large-scale study integrating gene expression and methylation data divided WNT-activated MBs into two subtypes: WNT $\alpha$ consists predominantly of children with chromosome 6 monosomy and WNT $\beta$ represents adults mainly with diploid chromosome 6 . The two subtypes harbor similar survival rates, although prognosis in adults is worse and underlying pathway activations are different $[58,59]$.

Stabilizing mutation of the CTNNB1 gene is the most common genetic alteration, present in $85-90 \%$ of all WNTactivated MBs $[8,60]$, frequently associated with chromosome 6 monosomy, occurring in about $70-80 \%$ of patients $[8,47$, 61]. In the large-scale MAGIC study, about $5 \%$ of WNTactivated MBs with typical WNT-signatures had neither CTNNB1 mutations nor chromosome 6 monosomy [62]. Thus, diagnosis solely based on these two events may miss up to $10-15 \%$ of WNT-activated MBs [8]. CTNNB1 mutations frequently occur with mutations of chromatin remodeling genes (CREBBP, TRRAP, and MED13) and/or subunits of the SWI/ SNF nucleosome-remodeling complex (SMARCA4, ARIDIA, and ARID2) suggesting that besides activation of CTNNB1, aberrant chromatin regulation may also be necessary for 


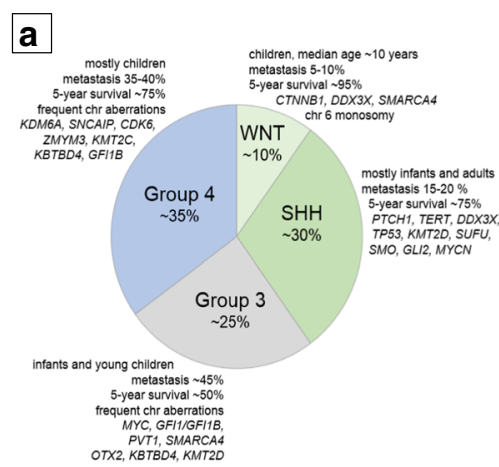

Fig 1 (a) The four molecular subgroups of MBs according to the current consensus and (b) the proposed risk stratification, based on [2]. WNTactivated (WNT-MB), SHH-activated (SHH-MB), and Group 3 and

WNT-MB $[8,60,61]$. Half of $\beta$-catenin mutated WNTactivated MBs harbor concurrent $D D X 3 X$ mutations [61], but these mutations are not subgroup-specific: $10-20 \%$ of SHH and $3 \%$ of Group 3 tumors also carry $D D X 3 X$ mutations [60]. $D D X 3 X$ participates in multiple cellular processes, including mRNA splicing, export, and translation [63], and its mutations are predicted to increase the proliferation rate of the lower rhombic lip progenitors [60]. $D D X 3 X$ is located on the $\mathrm{X}$ chromosome, and not unexpectedly its mutations have a strong male predominance [64]. The relatively frequent CSNK2B (wingless signaling pathway) and EPHA7 (cellular signaling) mutations are additional clinically actionable targets [8]. Although TP53 mutations are also relatively frequent, these have no prognostic significance in WNT-MBs $[8,61,65]$.

The rare germline mutation of $A P C$ on chromosome 5 as part of the inherited Turcot syndrome contributes to the development of familial WNT-MBs. APC mutations are coupled with distinct gene expression signatures, suggesting that $C T N N B 1$ and $A P C$ mutations are mutually exclusive and molecularly distinct [8]. Rare germline lesions in anaplastic lymphoma kinase gene $(A L K)$ have recently been identified in WNT-activated MBs [66], while other alternative mechanisms, such as mutations of $C D H 1$, may promote tumor development [60]. There are no frequent, targetable somatic copy number aberrations in WNT-MBs $[8,62]$.

\subsubsection{SHH-activated MBs}

SHH-MBs account for $~ 30 \%$ of all MBs with an intermediate prognosis (5-year OS of 70\%) [49] and are most frequently found in infants and adults, with relatively fewer childhood cases $[8,10,52]$. Age at diagnosis is associated with distinct molecular and clinical categories [57,67]. The majority of SHH-MBs are nodular/desmoplastic but can also have a classic or LCA histology, the latter especially frequent among children [54,68]. The nodular desmoplastic subtype predicts increased survival in infants $[44,69,70]$.
Group 4 MBs are distinguished by origin, demographics, genetic and molecular alterations, and clinical outcome

Over $95 \%$ of SHH-MBs contain at least one driver event. However, the types of mutations are highly variable [8, 68]. SHH-MBs have the highest, $14-20 \%$ prevalence of destructive germline mutations among all MBs. Li-Fraumeni syndrome is linked to hereditary TP53 mutations $(\sim 20 \%$ of all SHH-MB), most frequent among children aged 5-16, predisposing to multiple familial cancers and coupled with a low survival [71]. Li-Fraumeni syndrome-associated SHH-MBs have an exceptionally high mutational rate [72], and radiation therapy can accelerate tumor growth [73]. Gorlin syndrome is associated with mutations affecting PTCH1 and SUFU genes of the SHH-pathway [74], present in $21 \%$ of all infant SHHMBs, where radiation also increases the likelihood of secondary, mostly skin cancers [75].

Activating mutations almost permanently involve the SHH-signaling pathway [68], including the mutually exclusive and age-group specific PTCH1 ( 43\%), SUFU ( 10\%), and $S M O(\sim 9 \%)$ mutations $[8,60,68,72]$. SUFU and $S F O$ mutations are enriched in infants $(0-4$ years $)$ and adults, respectively, and the presence of $\mathrm{PTCH} 1$ mutations is roughly equal in all age groups [68]. In children, TP53 mutations are mutually exclusive with $\mathrm{PTCH} 1$ mutations but frequently cooccur with GLI2 and $M Y C N$ amplifications, essential regulators of transcription [8]. Loss of chromosome 17p loss is also frequent [68], as are TP53 mutations that interestingly do not confer a survival disadvantage [72]. TP53 mutational status separates SHH-MBs with distinct outcomes: tumors with TP53-wildtype are more frequent among adults and young children and are linked to favorable prognosis $(81 \% 5$-year OS). In contrast, TP53 mutations are typical among older children and are associated with dismal outcome (40\% 5year OS). TP53 mutations account for two-thirds of deaths in children older than 5 years. In SHH-MB, more than half of TP53-mutantion are germline [65]. Mutations of some genes are almost exclusively specific to the adult subgroup, including TERT promoter mutations that drive telomerase activity [76] or recurrent mutations of the PI3K/AKT/mTOR pathway [68]. Additional subgroup-specific molecular 
alterations affect chromatin modulation, histone acetyltransferase, or nuclear receptor corepressor complexes [77]. High expression often cannot be traced to specific mutations or chromosome aberrations; like in the case of cMET that is among the most frequently hypo- or hypermethylated genes in MBs [78].

\subsubsection{Group 3 and Group 4 MBs}

Group 3 MBs represent approximately 25\% of all cases (Fig. 1) with a peak of diagnosis between ages 3 and 5 years and is the deadliest of all MBs, with a 58\% 5-year OS in children and a $45 \%$ in infants $[9,13,52]$. Male to female ratio is about 2:1 [12]. Group 3 MBs are mostly classical, although $40 \%$ harbor LCA histology, assigning most LCA tumors to this subgroup [12]. The aggregation of multiple adverse circumstances, such as young age coupled with metastatic spread (up to 50\% of patients), the presence of MYC amplifications, and high rate of LCA histology, all contribute to the poor prognosis. $M Y C$-amplified tumors confer an especially short survival with only $20 \%$ of patients surviving 5 years postdiagnosis $[49,79]$. Absence of metastatic spread does not necessarily reflect good prognosis [67]; thus, standard-risk children with Group 3 disease may face under-treatment [52].

Group 4 is the most prevalent ( $35 \%$, Fig. 1$)$ and also the least understood subgroup [7,52] including about $45 \%$ of all childhood and $25 \%$ of adult cases with an overall intermediate prognosis (5-year overall survival 75-90\%) [7]. The prevalence is three times higher in males than in females [7, 52]. Outcome is excellent in patients with chromosome 11 loss where survival exceeds $90 \%$ [2]. Nevertheless, 30-40\% of Group 4 MB patients are diagnosed with metastases and treated for high-risk disease, with 5-year survival as low as $60 \%$ [2, 11, 52]. Adults with Group 4 MBs have a significantly worse prognosis compared to the SHH- or WNT-activated subtypes [58].

Group 3 and Group 4 MBs are genetically heterogeneous, not driven by well-defined, constitutively activated signaling pathways, and rarely have damaging germline mutations in known cancer predisposition genes [71]. Tetraploidy is a recurrent early genetic event, leading to an increased number of large-scale copy number gains [72]. The most frequent cytogenetic alterations in Group $3 \mathrm{MBs}$ include the loss of $17 \mathrm{p}$ (55\%) along with loss of $16 q(42 \%), 10 q(43 \%)$, and $9 q(21 \%)$ and the gain of $17 \mathrm{q}$ (in $58 \%$ of samples), 7 (39\%), and $1 \mathrm{q}$ (41\%) [52]. Somatic MYC (17\% in Group 3) and $M Y C N$ (6\% Group 4) amplifications are frequent driver events [62], and high MYC levels are associated with meager outcome $[49,80]$. Other recurrent genetic events in Group 3 MBs include $O T X 2$ and EZH2 amplifications, SMARCA4 mutations, GFIl enhancer activation, copy number alterations in TGF $\beta$ pathway genes, and mutations in Notch signaling genes [81]. Tetraploidy is also present in approximately $40 \%$ of Group 4 tumors with unknown prognostic significance [72].
Isochromosome 17q occurs in about $80 \%$ of Group 4 tumors, but it does not confer poor prognosis. Other major recurrent genetic events in Group 4 MBs include 8p loss (41\%), 10q loss (15\%), aberrations of $11 \mathrm{p}$ and 18q, gain of chromosome 7 (47\%), complete loss of one X chromosome in about $80 \%$ of females [49, 52, 67, 82], amplifications of $M Y C N$ and $C D K 6$, SNCAIP duplications, and mutations in genes responsible for chromatin modification, such as KDM6A [81].

\subsection{Emerging risk stratification models}

A 2015 consensus conference held in Heidelberg incorporated prognostic molecular markers and suggested a more refined risk stratification for non-infant tumors (ages 3-17). The proposed four categories include low, standard, high, and very high-risk MBs [2] (Fig. 1). The low-risk (survival >90\%) group slots in non-metastatic patients under the age of 16 with WNT-MBs [2], possibly including patients with incomplete resections [13]. Patients over 16 years of age may not be low-risk, and recommendations for patients harboring metastatic disease or LCA histology are unclear. Non-metastatic Group 4 patients with chromosome 11 loss (about one-third) and/or whole gain of chromosome 17 (about 5\%) also qualify as low-risk [11]. The standard-risk (survival 75-90\%) population includes non-metastatic SHH patients excluding TP53mutated or $M Y C N$ amplified tumors, non-metastatic Group 3 MBs with no MYC amplification, and non-metastatic Group 4 MBs without chromosome 11 loss [11, 51, 65]. The high-risk (50-75\% survival) cohort consists of all $M Y C N$-amplified SHH-activated MBs (regardless of the metastatic status): TP53 wild-type, non-infant metastatic SHH-activated and metastatic Group 4 MBs [11]. The very high-risk $(<50 \%$ survival) population includes SHH patients with TP53 mutations and metastatic Group 3 MBs with $M Y C$ amplifications [2, 11, 65]. The risk evaluation of non-metastatic but $M Y C$-amplified Group 3 tumors with an LCA histology or isochromosome $17 \mathrm{q}$ or Group $4 \mathrm{MBs}$ with anaplastic histology requires further clarifications [2].

Molecular classification of MBs is constantly evolving, and additional stratification schemes started to emerge based on genome-wide molecular approaches. A large-scale study integrating gene expression and methylation data by similarity network fusion divided each subgroup into further biologically and clinically relevant subtypes. The resulting 12 subtypes ( 2 in WNT, 4 in SHH, and 3 in both Group 3 and Group 4) are suggested to be different on the molecular, clinical, and prognostic levels [59]. Another study utilizing methylation signatures and unsupervised class discovery distinguished seven robust subtypes, all predictive of clinical outcome. The analysis splits current subgroups, except WNT, into further subtypes: SHH by an age-dependent manner into infant $(<4.3$ years $)$ and children cohorts while both Group 3 and Group 4 into high-risk (HR) and low-risk (LR) categories with dramatically 
different survival rates. Within each subtype, secondary molecular characteristics strongly influenced prognosis and resulted in four different risk categories from favorable to very high-risk. The overall model is suggested to outperform other MB risk stratifications [16]. Novel subtypes with specific genetic signatures were identified in another large-scale study utilizing somatic landscape and epigenetic analyses [8].

The discrepancies across classification schemes stem from diverse patient populations (children only or all ages), types of data utilized, and clustering methods. Still, the emerging differences hold promise for improved stratification and genotype-specific treatment. Nevertheless, well-planned prospective clinical trials are inevitable to reach a consensus across stratification models and to identify appropriate biomarkers.

\subsection{Molecular subgroup-specific treatment approaches}

\subsubsection{WNT-activated MBs}

WNT-MBs contain a leaky vascular endothelium that disrupts the blood-brain barrier (BBB) integrity. The lack of functional BBB increases penetration of systemic chemotherapy and contributes to the excellent prognosis seen in WNT-MB patients even in the presence of metastases [83]. The Wnt pathway has a crucial role in various developmental processes, including tissue regeneration and bone formation [84]. Targeting the Wnt pathway would interfere with such physiological mechanisms and could also eliminate the advantageous chemosensitivity of WNT-activated MBs. Consequently, targeted therapies against WNT-MBs are not being developed. Instead, current therapy de-escalation for low- or standard-risk WNT-MBs is tested by several clinical trials (Table 1). Trial NCT01878617 utilizes molecular subgroup allocation and clinical risk category at treatment selection and investigates therapy de-escalation for low-risk WNT-activated MBs. Another phase II trial (NCT02724579) studies the effects of reduced CSI and chemotherapy (no vincristine during radiotherapy and reduced-dose maintenance chemotherapy) on average-risk WNT-activated MBs defined by positive nuclear beta-catenin expression (by IHC), CTNNB1 mutations, and absence of $M Y C$ and $M Y C N$ amplifications (by FISH).

The SIOP PNET 5 phase II/III trial (NCT02066220) evaluates the efficacy of risk-dependent treatment adjustments. The aim is to confirm high event-free survival in patients with a low-risk profile defined by non-metastatic $\mathrm{MB}$ with total and near-total tumor resection, absence of $M Y C$ and $M Y C N$ amplifications and LCA histology, and nuclear beta-catenin immune positivity. Low-risk (WNT-activated) patients receive radiotherapy with a dose of 54 Gy to the primary tumor and 18.0 Gy to the craniospinal axis without carboplatin, followed by six cycles of reduced-intensity maintenance chemotherapy (consisting of three courses of cisplatin, CCNU, and vincristine alternating with three courses of cyclophosphamide and vincristine).

\subsubsection{SHH-activated MBs}

Inhibition of smoothened (SMO) offers avenues for a targeted subgroup-specific treatment strategy for SHH-activated MBs. SMO inhibition blocks downstream signaling, Gli translocation, and activation of Hedgehog target genes [85]. Most adult SHH-MB patients $(80 \%)$ carry PTCH1 or SMO mutations. Vismodegib (GDC-0449), a small molecule inhibitor of SMO, demonstrated particular efficacy against recurrent/ refractory MBs [86, 87]. Nevertheless frequent mutations downstream of SMO, such as mutations affecting $S U F U$ or GLI1, render most infants and children resistant to targeted vismodegib therapy [68]. Moreover, SMO inhibition hinders normal bone and teeth development in pediatric patients causing growth plate fusions that persist long after therapy cessation [88]. Preclinical efforts seeking targeted therapies against SHH-MBs also focus at epigenetic treatments with BET bromodomain inhibitors, inhibition of the G2/M regulators AURK and PLK, cMET inhibitors, strategies targeting stemlike cells, and interventions utilizing immunotherapies [77].

The currently recruiting phase II (NCT01878617) trial investigates the feasibility and toxicity of oral vismodegib maintenance therapy after conventional chemotherapy for standardrisk or high-risk newly diagnosed MBs in skeletally mature SHH-activated patients (Table 1). For recurrent/refractory SHH-activated MBs, further treatments and drug combinations are available (Table 2). A phase I trial organized by the St. Jude Children's Research Hospital (NCT03434262) investigates subgroup-specific doublet combinations including the CDK4/ 6 inhibitor ribociclib and SMO inhibitor sonidegib (LDE225) for adult $\mathrm{SHH}$-activated patients, with copy number loss of $9 \mathrm{q}$ or PTCH1 mutations and ribociclib and MEK-inhibitor trametinib for WNT- and SHH-activated MBs.

The Pediatric Brain Tumor Consortium Phase I/ II trial NCT03904862 evaluates the effects of CX-4945, silmitasertib sodium, a small molecule inhibitor of Casein kinase II (CK2) in skeletally immature (phase I) and skeletally mature (phase II), SHH-activated recurrent/ refractory $\mathrm{MB}$ patients, where subgroup identity is confirmed by a CLIA certified methylation-based assay. The St. Jude ELIOT (NCT04023669) phase I trial evaluates prexasertib (LY2606368), a targeted CHK1/2 inhibitor in combination with cyclophosphamide for recurrent/ refractory SHH-activated or Group 3/Group $4 \mathrm{MBs}$. Another trial, NCT03734913, explores ZSP1602, a SMO protein inhibitor, designed for adult patients with advanced MBs, regardless of SMO or Glil alteration status and molecular subgroup identity. 


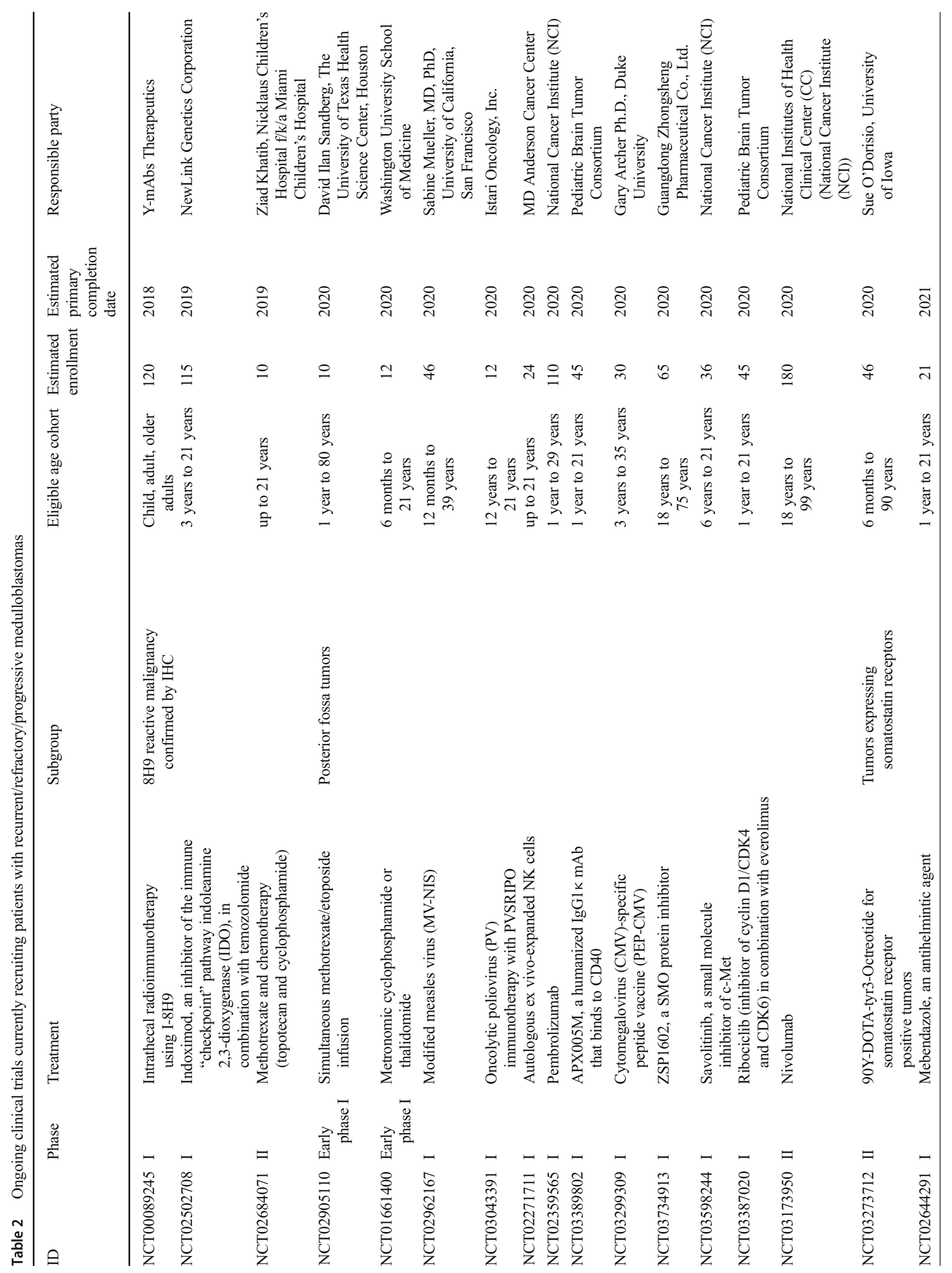




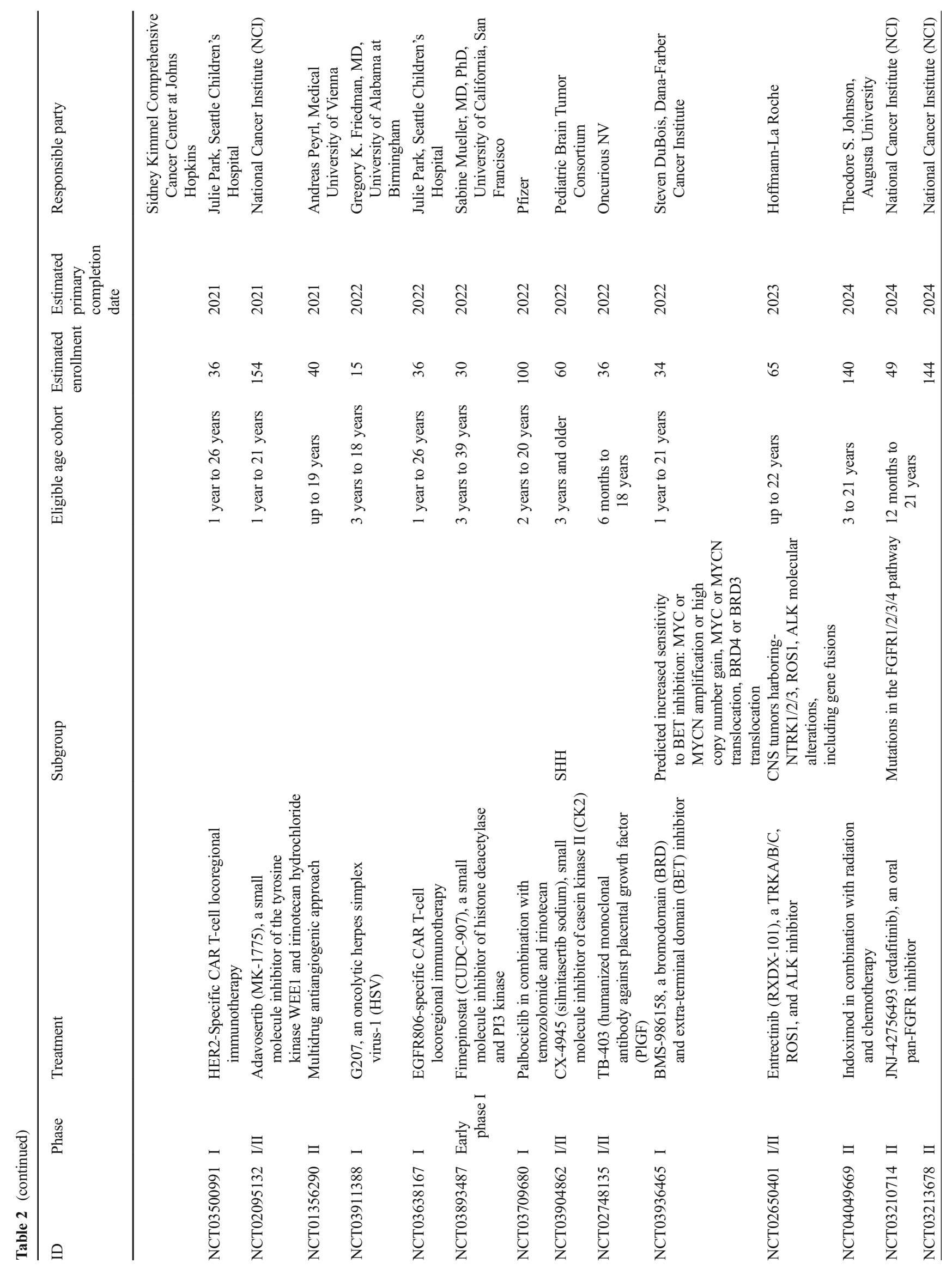




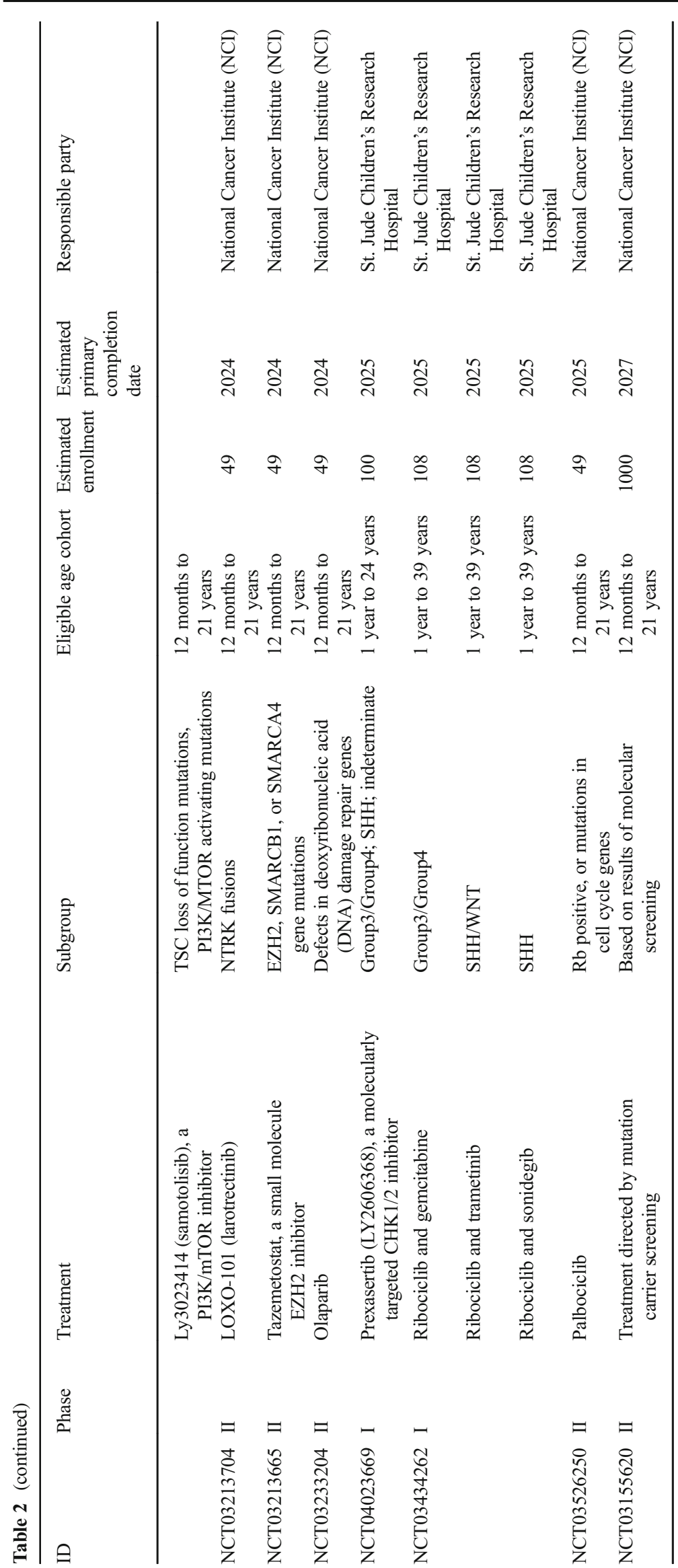




\subsubsection{Group 3/Group 4 MBs}

The limited understanding of tumorigenesis mechanisms hampers the development of targeted treatment strategies for Group 3 and Group 4 MBs. For newly diagnosed patients, the NCT01878617 trial offers risk-adapted treatment strategy: intermediate- and high-risk patients are exposed to new chemotherapy agents (pemetrexed and gemcitabine) after standard chemotherapy and risk-adapted radiotherapy (Table 1).

For recurrent and refractory MB patients, two trials offer treatments based on molecular subgrouping (Table 2). In NCT04023669, prexasertib (LY2606368), a targeted CHK1/ 2 inhibitor, is administered in combination with cyclophosphamide for Group 3, Group 4, and SHH-activated MBs or in combination with gemcitabine for Group 3/Group 4 MBs. The trial NCT03434262 investigates the combination of the cyclin-dependent kinase inhibitor ribociclib and gemcitabine for Group 3/Group 4 MBs.

In Group $3 \mathrm{MBs}$, preclinical studies focus at the inhibition of PI3K and mTOR signaling pathways, evaluate the synergistic activity between histone deacetylase inhibitors and PI3K inhibitors, assess the efficacy of CDK, PRKDC or BET bromodomain inhibitors, and test the effectiveness of anti-vascularization therapies [81]. Such experiments are no longer confined to preclinical model systems, and numerous early phase clinical trials started to explore these promising avenues in recurrent/refractory MBs, although therapeutic approaches rarely reflect the existing MB molecular classifications (Table 2).

\subsection{Refractory, recurrent, and progressive MBs}

Metastases and recurrence are the major barriers to therapeutic success, and disease recurrence is responsible for $95 \%$ of MBassociated deaths [89]. Patients who relapse after receiving upfront radiotherapy rarely survive (salvage rate $<10 \%$ ) despite the multitude of treatment options [90, 91]. Most SHH tumors recur in the tumor bed, suggesting that focusing therapies at the posterior fossa could be most profitable. By contrast, Group 3 and Group 4 MBs develop distant metastases irrespectively of the type of therapy administered at diagnosis [92]. Interestingly, Group 4 patients recur later compared to the other subtypes and survive longer after recurrence. Although metastases are rare in WNT-activated MBs, recurrence may occur locally with or without systemic dissemination $[91,92]$.

Molecular subgroup affiliation remains stable across samples collected at diagnosis and relapse [92, 93]. However, substantial genetic divergence occurs [94-96]. About twothirds of relapses acquire high-risk features, including TP53$M Y C$ gene family interactions. The presence of TP53-MYC interactions is associated with rapid disease progression [95]. Whole-genome sequencing identified significant increase in somatic mutational burden post-therapy: mutations of TP53 and other genes of the TP53 pathway, such as DYNC1H1 and losses of chr14q, occurred frequently, predominantly in recurrences of SHH-MBs [94]. Putative drug targets present at diagnosis were retained in only $44 \%$ of patients post-therapy, providing an explanation why most targeted therapies fail in MB [94].

The difficulty to manage recurrent/refractory/progressive MBs is reflected in the number of clinical trials dedicated to this population: about $80 \%$ of currently recruiting studies focuses on these heavily pretreated patients, although two-thirds of the identified trials are still in early phase (Table 2).

\subsubsection{Targeted therapies of CNS tumors irrespective of molecular subgrouping}

Several trials are not explicit to MBs and recruit patients with a range of advanced solid tumors including various neoplasm of the CNS. Such is the early phase I NCT03893487 trial exploring the ability of fimepinostat (CUDC-907), a small molecule inhibitor of histone deacetylase and PI3 kinase, to penetrate the blood brain barrier (BBB) of children and young adults with various CNS tumors, including recurrent MBs of any molecular subtypes.

The efficacy of cyclin-dependent kinase (CDK) inhibitors in treating hormone receptor positive, HER2-negative advanced breast cancer boosted the interest toward their further use in other tissue types. There are currently 103 active and recruiting clinical trials as listed at clinicaltrial.gov evaluating palbociclib alone in various tissue types including primary CNS tumors. The maximum tolerated dose of palbociclib (CDK4/6 inhibitor) combined with chemotherapy (irinotecan and temozolomide) is evaluated in the NCT0370968 phase I trial in children with solid and CNS tumors. A combined ribociclib (cyclin D1/CDK4 and CDK6 inhibitor) and everolimus treatment is utilized in the NCT03387020 phase I trial in children with recurrent/refractory primary CNS tumors, including MBs, with an intact RB1 protein.

Entrectinib (RXDX-101), a TRKA/B/C, ROS1, and ALK inhibitor, is being studied in a phase I/II trial (NCT02650401) recruiting children and young adults with recurrent/refractory CNS tumors harboring NTRK1/2/3, ROS1, and ALK molecular alterations, as confirmed by a CLIA-approved lab. A National Cancer Institute (NCI) sponsored phase I trial experiments with savolitinib, a small molecule inhibitor of c-Met (NCT03598244) in primary brain tumors including recurrent/ refractory MBs with MET pathway activations, defined as MET mutations/amplifications/fusions, HGF amplifications, and gain of chromosome 7. Another NCI sponsored phase I/ II study (NCT02095132) evaluates the activity of adavosertib (MK-1775), a small molecule inhibitor of the tyrosine kinase WEE1, combined with irinotecan hydrochloride in relapsed or refractory solid malignancies including CNS tumors. The 
study also aims to evaluate predictive biomarkers of adavosertib sensitivity, such as the expression of $M Y C$, $M Y C N, E Z H 2, H 2 A X$, and phosphorylated WEE1. The NCT03936465 trial evaluates the safety and dosing of the investigational drug BMS-986158, a bromodomain and BET inhibitor in pediatric solid tumors with molecular features predicted to increase sensitivity to BMS-986158, consisting of $M Y C$ and $M Y C N$ translocations and amplifications and $B R D 4$ or $B R D 3$ translocations. Additional ongoing early phase trials evaluating the safety and tolerability of novel treatment strategies are listed in Table 2.

\subsubsection{Targeted therapies irrespective of the tumor or tissue type}

There is an increasing tendency in oncology to explore the efficacy and safety of molecularly targeted agents for sample-specific genetic alterations, irrespectively of the tumor or tissue type (Table 2). Such is the NCI-COG Pediatric MATCH (Molecular Analysis for Therapy Choice) trial (NCT03155620) that evaluates experimental treatments targeting selected molecular alterations in children and adolescents with advanced solid tumors. Drug selection is based on the results of molecular screening with genome sequencing, with at least 20 patients in each treatment arm. Six phase II clinical trials concerning recurrent/refractory MBs are currently recruiting within the program: patients harboring mutations in the FGFR1/2/3/4 pathway may receive erdafitinib (JNJ-42756493), an oral pan-FGFR inhibitor (NCT03210714); MBs with TSC loss of function mutations or PI3K/mTOR activating mutations are treated with samotolisib (Ly3023414), a PI3K/mTOR inhibitor (NCT03213678); actionable NTRK fusions are treated with larotrectinib (LOXO-101) (NCT03213704); mutations in RB or in cell cycle genes are targeted by palbociclib (NCT03526250); tumors with defects in DNA damage repair genes are targeted by olaparib (NCT03233204); and EZH2, SMARCB1, or SMARCA4 gene mutations are treated with tazemetostat, a small molecule EZH2 inhibitor.

\subsection{Immunotherapies for advanced disease}

The expanding number of new trials investigating immunotherapies reflects recent tendencies in oncology. Currently, the number of phase I studies utilizing an immunotherapy-based and a targeted approach is equivalent (Table 2).

\subsubsection{Immune checkpoint inhibitors (ICls)}

Cancer cells upregulate immune checkpoints to escape T-cellmediated immune response [97]. Groundbreaking application of immune checkpoint inhibitors in numerous solid tumors, including metastatic melanoma and renal cancer [98, 99], generated interest in their applicability in CNS cancers. The approach is especially attractive for patients with advanced disease and limited options for therapy. The success of using ICIs is limited so far - of note, most studies are retrospective and observational, with a limited sample size and unselected patient population. The anti-PD-1 agent pembrolizumab did not show clinical or histologic efficacy in pretreated patients with progressive brain tumors [100], and PD-1 inhibition with nivolumab provided limited benefits for adult patients with recurrent high-grade gliomas [101]. A retrospective review identified survival advantage of nivolumab among pediatric patients with recurrent/refractory brain tumors, especially among PD-L1-positive patients with elevated tumor mutation burden [102]. A phase I clinical trial reported the safety of ipilimumab in pediatric patients with advanced solid tumors, mostly melanomas, with increased overall survival among those with immune-related toxicities [103].

Currently, two clinical trials are investigating blockade of classical inhibitory checkpoint pathways in MBs (Table 2). The goal of the NCT02359565 phase I trial is to assess the safety and efficacy of pembrolizumab in children and young adults with recurrent/refractory/progressive brain tumors including MBs. NCT03173950, a phase II trial, evaluates the effects of biweekly nivolumab administration on objective response rate and progression-free survival of adult patients with rare CNS tumors including MBs.

The B7 homolog 3 (B7-H3), also known as CD276, is also an important checkpoint molecule with an inhibitory function on T-cell activation [104]. The NCT00089245 phase I study evaluates the effectiveness of intrathecal radioimmunotherapy using radioactive iodine labeled antibody I-8H9 against B7$\mathrm{H} 3$, which, after internalization, induces cell death.

In addition to CTLA4, PD-1, and PD-L1 inhibitors, the next generation of immune-checkpoint inhibitors is focusing on other immune pathways. Molecules of the co-stimulatory pathways augment the immunological response against tumor cells. Such is the surface receptor CD40, a TNF receptor family member expressed by APCs and B cells, that stimulates cytokine expression and activation of $\mathrm{T}$ cells and induces tumor cell death [105]. CD40 has also direct cytotoxic effects on CD40-positive tumor cells. APX005M, a humanized IgG1 K monoclonal antibody agonist of CD40 is being evaluated in a phase I pediatric trial (NCT03389802) in patients with recurrent/refractory primary malignant CNS tumors.

Indoleamine 2,3-dioxygenase (IDO) is a tryptophandegrading enzyme, and the produced active metabolites increase T-reg activity while decrease the activity of CD8 T cells, leading to an immunosuppressed tumor microenvironment and enhanced immune escape. IDO is frequently overexpressed in various tumor types [106] and is also associated with poor outcome and resistance to chemotherapy [107]. Indoximod, an inhibitor of the IDO pathway, is being studied with concomitant use of temozolomide in a phase I 
pediatric trial (NCT02502708) with an estimated completion date in December 2019. Additionally, in an NCI-funded phase II trial (NCT04049669), indoximod complemented with oral temozolomide is given to children and young adults both eligible and not-eligible for partial re-irradiation with progressive brain cancers.

\subsubsection{Oncolytic viruses}

Cancer therapy utilizing oncolytic viruses (OVs) has several advantages over traditional approaches: OVs replicate selectively only in cancerous but not in normal cells, and after infecting a few cells, OVs quickly spread through the entire tumor. The antitumor response is based on a dual mechanism of action: first, OVs induce direct lysis of tumor cells, and second, as a result, the release of neoantigens to the tumor microenvironment triggers activation of the immune system, facilitating tumor eradication [108]. Based on promising results from preclinical studies, several types of viruses are being investigated in the treatment of pediatric brain tumors [109].

A single injection of a genetically engineered herpes simplex virus (HSV) variant, rRp450 to orthotopic mouse xenografts representing Group 3 and $4 \mathrm{MB}$ cells, prolonged survival and had the ability to bioactivate the prodrug cyclophosphamide within the tumor microenvironment [110]. Another set of engineered variants of the HSV, G207, and M002 displayed antitumor activity and prolonged survival of mice bearing xenografts originating from the most aggressive Group 3 or 4 pediatric MB subgroups [111]. The safety of the G207 HSV-variant augmented with radiation has already been determined in a phase I trials in adult patients with recurrent high-grade gliomas [112]. The primary HSV entry receptor nectin-1 (CD111), an adhesion molecule, is expressed in significantly higher amounts in pediatric tumor cells compared to adults and displays sensitivity to the virus in vitro, requiring a substantially lower dose [113]. The results suggest that HSV treatment could be sufficiently effective for treating pediatric brain cancers. Accordingly, a currently recruiting phase I trial (NCT03911388) evaluates the effects of engineered HSV G207 alone or in combination with a single low-dose radiation in children with recurrent/ refractory brain tumors, including recurrent MBs.

Measles virus (MV) is a negative strand RNA virus that induces the fusion of neighboring cells leading to the development of giant, metabolically active, multinucleated aggregates, called syncytia, which contribute to cell death [114]. An MV that expresses thyroidal sodium iodide symporter (NIS) has been engineered to monitor viral replication - the expression of NIS also enhanced therapeutic efficacy [114]. There is currently a phase I study (NCT02962167) that aims to evaluate safety and dosing of MV-NIS for the treatment of children and young adults with recurrent MBs or recurrent atypical teratoid rhabdoid tumors (ATRT). For locally recurrent disease, the virus is introduced directly to the tumor bed. For disseminated MB, MV-NIS is injected to the subarachnoid space through lumbar puncture.

Targeted elimination may also be achieved through the highly attenuated polio/rhinovirus recombinant PVSRIPO that recognizes the poliovirus receptor $\mathrm{CD} 155$ widely expressed by both cancerous cells and components of the tumor microenvironment [115]. A phase I dose-finding and toxicity study on adults with recurrent supratentorial WHO grade IV malignant gliomas treated by intratumoral delivery of the recombinant polio/rhinovirus chimera identified better survival outcome compared to historical controls [116]. Following a similar approach, a current phase Ib pediatric study (NCT03043391) investigates the safety and dosing of PVSRIPO by convection-enhanced delivery (CED) using an intracerebral catheter in WHO grade III, grade IV gliomas, and other brain tumors including recurrent MBs.

Glioblastomas are lethal brain tumors with no specific therapy. Cytomegalovirus (CMV) antigens are almost universally present and homogeneously expressed in glioblastomas compared to normal brain tissues. Thus, CMV presence provides an excellent opportunity to subvert these immunogenic viral proteins to be tumor-specific targets [117]. A cost effective, twocomponent CMV-specific multi-epitope peptide vaccine (PEPCMV) has been created including a synthetic long peptide of 26 amino acid residues from human pp65 and a neutralizing antibody epitope from human CMV glycoprotein B. The phase I PRiME clinical trial (NCT03299309) evaluates the safety of PEP-CMV in pediatric and young adult patients with recurrent MBs and malignant gliomas. Vaccination is preceded by temozolomide treatment to augment immunogenicity, and patients older than 18 years of age receive an intradermal tetanus vaccine booster to precondition the immune system.

\subsubsection{CAR-T therapy}

In the CAR-T therapy, genetically engineered T-cell expressing artificial chimeric antigen receptors (CAR) with both antigen-binding and T-cell activating properties are utilized. CAR-T therapy resulted in breakthroughs in treating hematological malignancies, but solid tumors pose a wide array of challenges, such as finding tumor-associated antigens enriched in tumors but not expressed in normal tissues [118]. HER2 is frequently overexpressed in MBs, and intraventricular administration of autologous HER2-CAR T cells effectively cleared orthotopically implanted MBs in the posterior fossa originating from Daoy and D283 tumor cells in a preclinical mouse MB model [119]. In the BrainChild-01 phase I trial (NCT03500991) of Seattle Children's Hospital, autologous CD4+ and CD8+ T cells lentivirally transduced to express HER2-specific chimeric antigen receptor and EGFRt (a truncated form of the human epidermal growth factor receptor) are investigated. Engineered $\mathrm{T}$ cells are delivered to 
the tumor resection cavity or the ventricular system of recurrent/refractory MB patients with HER2-positive disease. By this delivery method, $\mathrm{T}$ cells do not need to penetrate the blood-brain barrier, and this can presumably provide higher efficiency compared to intravenous infusion. In another Seattle Children's Hospital phase I trial (NCT03638167), transduced CAR-T cells expressing the EGFR806 specificCAR and EGFRt are infused into pediatric and young adult patients with histologically diagnosed EGFR positive recurrent/refractory CNS tumors.

\subsubsection{Natural killer cells}

Natural killer (NK) cells play a major role in the immune defense against malignant disease by recognizing a broad spectrum of tumor cells without specific antigen identification [120]. NK cells are controlled by both activating and inhibitory receptors, and $\mathrm{MB}$ cell lines express specific ligands that are able to trigger NK activation, enabling the lysis of MB cell lines in vitro regardless of the presence or absence of the stem cell marker CD133 [121]. However, complete elimination is unlike due to inhibitory signals generated by the tumor cells. Several studies investigate ex vivo propagated, transduced, or otherwise modified NK cells, such as cells expressing dominant-negative TGF- $\beta$ receptor II (DNRII) [122]. In a currently recruiting phase I clinical trial by the MD Anderson Cancer Center (NCT02271711), ex vivo propagated autologous NK cells with artificial antigen-presenting cells (aAPC) are being administered directly to the brain of pediatric patients with recurrent/refractory MBs.

\section{Conclusions}

Recent advances in MB research have expanded our understanding of MB pathogenesis and expanded the list of potential biomarkers with prognostic significance. Prospective trials are needed to confirm the validity of molecularly grounded stratifications, eventually offering more precise treatment strategies. The ongoing transition toward molecularly guided clinical interventions is slow, especially for newly diagnosed MB patients. Clinical trials aim to fine-tune invasive radioand chemotherapies to reduce intervention-related morbidity in low- or standard-risk patients, with a particular focus on young children and rare MBs affecting adults. Studies recruiting newly diagnosed patients exploit molecular markers to some extent, especially to distinguish WNT-activated MBs utilizing mandatory testing for CTNNB1 mutational status or IHC positivity. Evaluation of the presence of MYC or MYCN amplifications to identify high-risk patients also became standard procedure. Nevertheless, incorporation of a full molecular analysis for newly diagnosed patients utilizing both the clinical risk and the tumor's molecular subgroup allocation for therapy selection is limited to a single trial (NCT01878617).

It is especially vital to unravel novel, druggable pathways for subgroups with frequent metastases and low rates of recurrent molecular alterations, such as Group 3 and Group 4 MBs. For high-risk patients, clinical trials evaluate the effects of therapy intensification and novel chemotherapy drugs. Emergence of innovative concepts, such as integration of proteomic approaches into existing models of tumorigenesis, may expand translational opportunities [123].

The proportion of targeted and immunotherapies in recurrent/refractory MBs is increasing compared to cytotoxic strategies. Several trials consider molecular subgrouping, and novel targeted therapies are being explored irrespectively of the tumor or tissue type. Immune therapies utilize a wide range of treatment options, from immune checkpoint inhibitors, CAR-T therapies, and NK-cells to oncolytic viruses. While most trials are in an early phase, there is hope for therapeutic breakthroughs in historically difficult to treat recurrent/refractory MBs in the next decade.

Acknowledgements Open access funding provided by Semmelweis University (SE).

Funding information The study was supported by the KH-129581, 2018-1.3.1-VKE-2018-00032 and the 2018-2.1.17-TET-KR-00001 grants of the National Research, Development and Innovation Office, Hungary.

\section{Compliance with ethical standards}

Conflict of interest The authors declare that they have no conflict of interest.

Open Access This article is licensed under a Creative Commons Attribution 4.0 International License, which permits use, sharing, adaptation, distribution and reproduction in any medium or format, as long as you give appropriate credit to the original author(s) and the source, provide a link to the Creative Commons licence, and indicate if changes were made. The images or other third party material in this article are included in the article's Creative Commons licence, unless indicated otherwise in a credit line to the material. If material is not included in the article's Creative Commons licence and your intended use is not permitted by statutory regulation or exceeds the permitted use, you will need to obtain permission directly from the copyright holder. To view a copy of this licence, visit http://creativecommons.org/licenses/by/4.0/.

\section{References}

1. Smoll, N. R., \& Drummond, K. J. (2012). The incidence of medulloblastomas and primitive neurectodermal tumours in adults and children. Journal of Clinical Neuroscience, 19(11), 15411544. https://doi.org/10.1016/j.jocn.2012.04.009.

2. Ramaswamy, V., Remke, M., Bouffet, E., Bailey, S., Clifford, S. C., Doz, F., Kool, M., Dufour, C., Vassal, G., Milde, T., Witt, O., von Hoff, K., Pietsch, T., Northcott, P. A., Gajjar, A., Robinson, G. 
W., Padovani, L., André, N., Massimino, M., Pizer, B., Packer, R., Rutkowski, S., Pfister, S. M., Taylor, M. D., \& Pomeroy, S. L. (2016). Risk stratification of childhood medulloblastoma in the molecular era: The current consensus. Acta Neuropathologica, 131(6), 821-831. https://doi.org/10.1007/s00401-016-1569-6.

3. Salloum, R., Chen, Y., Yasui, Y., Packer, R., Leisenring, W., Wells, E., King, A., Howell, R., Gibson, T. M., Krull, K. R., Robison, L. L., Oeffinger, K. C., Fouladi, M., \& Armstrong, G. T. (2019). Late morbidity and mortality among medulloblastoma survivors diagnosed across three decades: A report from the childhood cancer survivor study. Journal of Clinical Oncology, 37(9), 731-740. https://doi.org/10.1200/jco.18.00969.

4. Pui, C. H., Gajjar, A. J., Kane, J. R., Qaddoumi, I. A., \& Pappo, A. S. (2011). Challenging issues in pediatric oncology. Nature Reviews. Clinical Oncology, 8(9), 540-549. https://doi.org/10. 1038/nrclinonc.2011.95.

5. Ning, M. S., Perkins, S. M., Dewees, T., \& Shinohara, E. T. (2015). Evidence of high mortality in long term survivors of childhood medulloblastoma. Journal of Neuro-Oncology, 122(2), 321327. https://doi.org/10.1007/s11060-014-1712-y.

6. Louis, D. N., Perry, A., Reifenberger, G., von Deimling, A., Figarella-Branger, D., Cavenee, W. K., Ohgaki, H., Wiestler, O. D., Kleihues, P., \& Ellison, D. W. (2016). The 2016 World Health Organization classification of tumors of the central nervous system: A summary. Acta Neuropathologica, 131(6), 803-820. https://doi.org/10.1007/s00401-016-1545-1.

7. Taylor, M. D., Northcott, P. A., Korshunov, A., Remke, M., Cho, Y. J., Clifford, S. C., Eberhart, C. G., Parsons, D. W., Rutkowski, S., Gajjar, A., Ellison, D. W., Lichter, P., Gilbertson, R. J., Pomeroy, S. L., Kool, M., \& Pfister, S. M. (2012). Molecular subgroups of medulloblastoma: The current consensus. Acta Neuropathologica, 123(4), 465-472. https://doi.org/10.1007/ s00401-011-0922-z.

8. Northcott, P. A., Buchhalter, I., Morrissy, A. S., Hovestadt, V., Weischenfeldt, J., Ehrenberger, T., Gröbner, S., Segura-Wang, M., Zichner, T., Rudneva, V. A., Warnatz, H. J., Sidiropoulos, N., Phillips, A. H., Schumacher, S., Kleinheinz, K., Waszak, S. M., Erkek, S., Jones, D. T. W., Worst, B. C., Kool, M., Zapatka, M., Jäger, N., Chavez, L., Hutter, B., Bieg, M., Paramasivam, N., Heinold, M., Gu, Z., Ishaque, N., Jäger-Schmidt, C., Imbusch, C. D., Jugold, A., Hübschmann, D., Risch, T., Amstislavskiy, V., Gonzalez, F. G. R., Weber, U. D., Wolf, S., Robinson, G. W., Zhou, X., Wu, G., Finkelstein, D., Liu, Y., Cavalli, F. M. G., Luu, B., Ramaswamy, V., Wu, X., Koster, J., Ryzhova, M., Cho, Y. J., Pomeroy, S. L., Herold-Mende, C., Schuhmann, M., Ebinger, M., Liau, L. M., Mora, J., McLendon, R., Jabado, N., Kumabe, T., Chuah, E., Ma, Y., Moore, R. A., Mungall, A. J., Mungall, K. L., Thiessen, N., Tse, K., Wong, T., Jones, S. J. M., Witt, O., Milde, T., von Deimling, A., Capper, D., Korshunov, A., Yaspo, M. L., Kriwacki, R., Gajjar, A., Zhang, J., Beroukhim, R., Fraenkel, E., Korbel, J. O., Brors, B., Schlesner, M., Eils, R., Marra, M. A., Pfister, S. M., Taylor, M. D., \& Lichter, P. (2017). The whole-genome landscape of medulloblastoma subtypes. Nature, 547(7663), 311-317. https://doi.org/10.1038/ nature22973.

9. Northcott, P. A., Jones, D. T., Kool, M., Robinson, G. W., Gilbertson, R. J., Cho, Y. J., Pomeroy, S. L., Korshunov, A., Lichter, P., Taylor, M. D., \& Pfister, S. M. (2012). Medulloblastomics: The end of the beginning. Nature Reviews. Cancer, 12(12), 818-834. https://doi.org/10.1038/nrc3410.

10. Gajjar, A. J., \& Robinson, G. W. (2014). Medulloblastomatranslating discoveries from the bench to the bedside. Nature Reviews. Clinical Oncology, 11(12), 714-722. https://doi.org/10. 1038/nrclinonc.2014.181.

11. Shih, D. J., Northcott, P. A., Remke, M., Korshunov, A., Ramaswamy, V., Kool, M., Luu, B., Yao, Y., Wang, X., Dubuc,
A. M., Garzia, L., Peacock, J., Mack, S. C., Wu, X., Rolider, A., Morrissy, A. S., Cavalli, F. M., Jones, D. T., Zitterbart, K., Faria, C. C., Schüller, U., Kren, L., Kumabe, T., Tominaga, T., Shin Ra, Y., Garami, M., Hauser, P., Chan, J. A., Robinson, S., Bognár, L., Klekner, A., Saad, A. G., Liau, L. M., Albrecht, S., Fontebasso, A., Cinalli, G., de Antonellis, P., Zollo, M., Cooper, M. K., Thompson, R. C., Bailey, S., Lindsey, J. C., di Rocco, C., Massimi, L., Michiels, E. M., Scherer, S. W., Phillips, J. J., Gupta, N., Fan, X., Muraszko, K. M., Vibhakar, R., Eberhart, C. G., Fouladi, M., Lach, B., Jung, S., Wechsler-Reya, R. J., FèvreMontange, M., Jouvet, A., Jabado, N., Pollack, I. F., Weiss, W. A., Lee, J. Y., Cho, B. K., Kim, S. K., Wang, K. C., Leonard, J. R., Rubin, J. B., de Torres, C., Lavarino, C., Mora, J., Cho, Y. J., Tabori, U., Olson, J. M., Gajjar, A., Packer, R. J., Rutkowski, S., Pomeroy, S. L., French, P. J., Kloosterhof, N. K., Kros, J. M., van Meir, E., Clifford, S. C., Bourdeaut, F., Delattre, O., Doz, F. F., Hawkins, C. E., Malkin, D., Grajkowska, W. A., Perek-Polnik, M., Bouffet, E., Rutka, J. T., Pfister, S. M., \& Taylor, M. D. (2014). Cytogenetic prognostication within medulloblastoma subgroups. Journal of Clinical Oncology, 32(9), 886-896. https://doi. org/10.1200/jco.2013.50.9539.

12. Northcott, P. A., Korshunov, A., Witt, H., Hielscher, T., Eberhart, C. G., Mack, S., et al. (2011). Medulloblastoma comprises four distinct molecular variants. Journal of Clinical Oncology, 29(11), 1408-1414. https://doi.org/10.1200/jco.2009.27.4324.

13. Thompson, E. M., Hielscher, T., Bouffet, E., Remke, M., Luu, B., Gururangan, S., et al. (2016). Prognostic value of medulloblastoma extent of resection after accounting for molecular subgroup: A retrospective integrated clinical and molecular analysis. The Lancet Oncology, 17(4), 484-495. https://doi.org/10.1016/ s1470-2045(15)00581-1.

14. Thompson, E. M., Bramall, A., Herndon 2nd, J. E., Taylor, M. D., \& Ramaswamy, V. (2018). The clinical importance of medulloblastoma extent of resection: A systematic review. Journal of Neuro-Oncology, 139(3), 523-539. https://doi.org/10.1007/ s11060-018-2906-5.

15. Wolden, S. L., Dunkel, I. J., Souweidane, M. M., Happersett, L., Khakoo, Y., Schupak, K., Lyden, D., \& Leibel, S. A. (2003). Patterns of failure using a conformal radiation therapy tumor bed boost for medulloblastoma. Journal of Clinical Oncology, 21(16), 3079-3083. https://doi.org/10.1200/jco.2003.11.140.

16. Schwalbe, E. C., Lindsey, J. C., Nakjang, S., Crosier, S., Smith, A. J., Hicks, D., et al. Novel molecular subgroups for clinical classification and outcome prediction in childhood medulloblastoma: A cohort study. The Lancet Oncology, 18(7), 958-971. https://doi. org/10.1016/S1470-2045(17)30243-7.

17. Chin, A. L., Moding, E. J., Donaldson, S. S., Gibbs, I. C., Soltys, S. G., Hiniker, S. M., \& Pollom, E. L. (2018). Survival impact of postoperative radiotherapy timing in pediatric and adolescent medulloblastoma. Neuro-Oncology, 20(8), 1133-1141. https://doi. org/10.1093/neuonc/noy001.

18. Packer, R. J., Goldwein, J., Nicholson, H. S., Vezina, L. G., Allen, J. C., Ris, M. D., Muraszko, K., Rorke, L. B., Wara, W. M., Cohen, B. H., \& Boyett, J. M. (1999). Treatment of children with medulloblastomas with reduced-dose craniospinal radiation therapy and adjuvant chemotherapy: A Children's Cancer Group Study. Journal of Clinical Oncology, 17(7), 2127-2136. https://doi.org/ 10.1200/jco.1999.17.7.2127.

19. Merchant, T. E., Kun, L. E., Krasin, M. J., Wallace, D., Chintagumpala, M. M., Woo, S. Y., Ashley, D. M., Sexton, M., Kellie, S. J., Ahern, V., \& Gajjar, A. (2008). Multi-institution prospective trial of reduced-dose craniospinal irradiation (23.4 Gy) followed by conformal posterior fossa (36 Gy) and primary site irradiation (55.8 Gy) and dose-intensive chemotherapy for average-risk medulloblastoma. International Journal of 
Radiation Oncology, Biology, Physics, 70(3), 782-787. https:// doi.org/10.1016/j.ijrobp.2007.07.2342.

20. Wahba, H. A., Abu-Hegazy, M., Wasel, Y., Ismail, E. I., \& Zidan, A. S. (2013). Adjuvant chemotherapy after reduced craniospinal irradiation dose in children with average-risk medulloblastoma: A 5-year follow-up study. Journal of BUON, 18(2), 425-429.

21. Gajjar, A., Chintagumpala, M., Ashley, D., Kellie, S., Kun, L. E., Merchant, T. E., Woo, S., Wheeler, G., Ahern, V., Krasin, M. J., Fouladi, M., Broniscer, A., Krance, R., Hale, G. A., Stewart, C. F., Dauser, R., Sanford, R. A., Fuller, C., Lau, C., Boyett, J. M., Wallace, D., \& Gilbertson, R. J. (2006). Risk-adapted craniospinal radiotherapy followed by high-dose chemotherapy and stem-cell rescue in children with newly diagnosed medulloblastoma $(\mathrm{St}$ Jude Medulloblastoma-96): Long-term results from a prospective, multicentre trial. The Lancet Oncology, 7(10), 813-820. https:// doi.org/10.1016/s1470-2045(06)70867-1.

22. Packer, R. J., Zhou, T., Holmes, E., Vezina, G., \& Gajjar, A. (2013). Survival and secondary tumors in children with medulloblastoma receiving radiotherapy and adjuvant chemotherapy: Results of Children's Oncology Group trial A9961. NeuroOncology, 15(1), 97-103. https://doi.org/10.1093/neuonc/nos267.

23. Ris, M. D., Packer, R., Goldwein, J., Jones-Wallace, D., \& Boyett, J. M. (2001). Intellectual outcome after reduced-dose radiation therapy plus adjuvant chemotherapy for medulloblastoma: A Children's Cancer Group study. Journal of Clinical Oncology, 19(15), 3470-3476. https://doi.org/10.1200/jco.2001.19.15.3470.

24. Thomas, P. R., Deutsch, M., Kepner, J. L., Boyett, J. M., Krischer, J., Aronin, P., et al. (2000). Low-stage medulloblastoma: Final analysis of trial comparing standard-dose with reduced-dose neuraxis irradiation. Journal of Clinical Oncology, 18(16), 3004-3011. https://doi.org/10.1200/jco.2000.18.16.3004.

25. Michalski, J., Vezina, G., Burger, P., Gajjar, A., Pollack, I., Merchant, T., et al. (2016). MB-109: Preliminary results of COG ACNS0331: A phase III trial of involved field radiotherapy (IFRT) and low dose craniospinal irradiation (LD-CSI) with chemotherapy in average risk medulloblastoma: a report from the children's oncology group. Neuro-Oncology, 18(Suppl 3), iii122. https://doi.org/10.1093/neuonc/now076.104.

26. Kann, B. H., Park, H. S., Lester-Coll, N. H., Yeboa, D. N., Benitez, V., Khan, A. J., Bindra, R. S., Marks, A. M., \& Roberts, K. B. (2016). Postoperative radiotherapy patterns of care and survival implications for medulloblastoma in young children. JAMA Oncology, 2(12), 1574-1581. https://doi.org/10.1001/ jamaoncol.2016.2547.

27. Yock, T. I., Yeap, B. Y., Ebb, D. H., Weyman, E., Eaton, B. R., Sherry, N. A., Jones, R. M., MacDonald, S., Pulsifer, M. B., Lavally, B., Abrams, A. N., Huang, M. S., Marcus, K. J., \& Tarbell, N. J. (2016). Long-term toxic effects of proton radiotherapy for paediatric medulloblastoma: A phase 2 single-arm study. The Lancet Oncology, 17(3), 287-298. https://doi.org/10.1016/ s1470-2045(15)00167-9.

28. Moeller, B. J., Chintagumpala, M., Philip, J. J., Grosshans, D. R., McAleer, M. F., Woo, S. Y., et al. (2011). Low early ototoxicity rates for pediatric medulloblastoma patients treated with proton radiotherapy. Radiation Oncology, 6, 58. https://doi.org/10.1186/ 1748-717x-6-58

29. St Clair, W. H., Adams, J. A., Bues, M., Fullerton, B. C., La Shell, S., Kooy, H. M., et al. (2004). Advantage of protons compared to conventional X-ray or IMRT in the treatment of a pediatric patient with medulloblastoma. International Journal of Radiation Oncology, Biology, Physics, 58(3), 727-734. https://doi.org/10. 1016/s0360-3016(03)01574-8.

30. Kahalley, L. S., Ris, M. D., Grosshans, D. R., Okcu, M. F., Paulino, A. C., Chintagumpala, M., Moore, B. D., Guffey, D., Minard, C. G., Stancel, H. H., \& Mahajan, A. (2016). Comparing intelligence quotient change after treatment with proton versus photon radiation therapy for pediatric brain tumors. Journal of Clinical Oncology, 34(10), 1043-1049. https://doi.org/ 10.1200/jco.2015.62.1383.

31. Hoff, K. V., Hinkes, B., Gerber, N. U., Deinlein, F., Mittler, U., Urban, C., Benesch, M., Warmuth-Metz, M., Soerensen, N., Zwiener, I., Goette, H., Schlegel, P. G., Pietsch, T., Kortmann, R. D., Kuehl, J., \& Rutkowski, S. (2009). Long-term outcome and clinical prognostic factors in children with medulloblastoma treated in the prospective randomised multicentre trial HIT'91. European Journal of Cancer, 45(7), 1209-1217. https://doi.org/ 10.1016/j.ejca.2009.01.015.

32. Kortmann, R. D., Kuhl, J., Timmermann, B., Mittler, U., Urban, C., Budach, V., et al. (2000). Postoperative neoadjuvant chemotherapy before radiotherapy as compared to immediate radiotherapy followed by maintenance chemotherapy in the treatment of medulloblastoma in childhood: Results of the German prospective randomized trial HIT '91. International Journal of Radiation Oncology, Biology, Physics, 46(2), 269-279. https://doi.org/10. 1016/s0360-3016(99)00369-7.

33. Packer, R. J., Gajjar, A., Vezina, G., Rorke-Adams, L., Burger, P. C., Robertson, P. L., Bayer, L., LaFond, D., Donahue, B. R., Marymont, M. H., Muraszko, K., Langston, J., \& Sposto, R. (2006). Phase III study of craniospinal radiation therapy followed by adjuvant chemotherapy for newly diagnosed average-risk medulloblastoma. Journal of Clinical Oncology, 24(25), 4202-4208. https://doi.org/10.1200/jco.2006.06.4980.

34. Packer, R. J., Rood, B. R., \& MacDonald, T. J. (2003). Medulloblastoma: Present concepts of stratification into risk groups. Pediatric Neurosurgery, 39(2), 60-67. https://doi.org/10. 1159/000071316.

35. Jakacki, R. I., Burger, P. C., Zhou, T., Holmes, E. J., Kocak, M., Onar, A., Goldwein, J., Mehta, M., Packer, R. J., Tarbell, N., Fitz, C., Vezina, G., Hilden, J., \& Pollack, I. F. (2012). Outcome of children with metastatic medulloblastoma treated with carboplatin during craniospinal radiotherapy: A Children's Oncology Group Phase I/II study. Journal of Clinical Oncology, 30(21), 26482653. https://doi.org/10.1200/jco.2011.40.2792.

36. Sung, K. W., Lim, D. H., Son, M. H., Lee, S. H., Yoo, K. H., Koo, H. H., Kim, J. H., Suh, Y. L., Joung, Y. S., \& Shin, H. J. (2013). Reduced-dose craniospinal radiotherapy followed by tandem high-dose chemotherapy and autologous stem cell transplantation in patients with high-risk medulloblastoma. Neuro-Oncology, 15(3), 352-359. https://doi.org/10.1093/neuonc/nos304.

37. Bull, K. S., Spoudeas, H. A., Yadegarfar, G., \& Kennedy, C. R. (2007). Reduction of health status 7 years after addition of chemotherapy to craniospinal irradiation for medulloblastoma: A follow-up study in PNET 3 trial survivors on behalf of the CCLG (formerly UKCCSG). Journal of Clinical Oncology, 25(27), 4239-4245. https://doi.org/10.1200/jco.2006.08.7684.

38. von Bueren, A. O., Kortmann, R. D., von Hoff, K., Friedrich, C., Mynarek, M., Muller, K., et al. (2016). Treatment of children and adolescents with metastatic medulloblastoma and prognostic relevance of clinical and biologic parameters. Journal of Clinical Oncology, 34(34), 4151-4160. https://doi.org/10.1200/jco.2016. 67.2428 .

39. Lafay-Cousin, L., Smith, A., Chi, S. N., Wells, E., Madden, J., Margol, A., Ramaswamy, V., Finlay, J., Taylor, M. D., Dhall, G., Strother, D., Kieran, M. W., Foreman, N. K., Packer, R. J., \& Bouffet, E. (2016). Clinical, pathological, and molecular characterization of infant medulloblastomas treated with sequential highdose chemotherapy. Pediatric Blood \& Cancer, 63(9), 15271534. https://doi.org/10.1002/pbc.26042.

40. Cohen, B. H., Geyer, J. R., Miller, D. C., Curran, J. G., Zhou, T., Holmes, E., et al. (2015). Pilot study of intensive chemotherapy with peripheral hematopoietic cell support for children less than 3 years of age with malignant brain tumors, the CCG-99703 phase I/ 
II study. A report from the Children's Oncology Group. Pediatric Neurology, 53(1), 31-46. https://doi.org/10.1016/j.pediatrneurol. 2015.03.019.

41. Rutkowski, S., Bode, U., Deinlein, F., Ottensmeier, H., WarmuthMetz, M., Soerensen, N., Graf, N., Emser, A., Pietsch, T., Wolff, J. E., Kortmann, R. D., \& Kuehl, J. (2005). Treatment of early childhood medulloblastoma by postoperative chemotherapy alone. The New England Journal of Medicine, 352(10), 978-986. https://doi. org/10.1056/NEJMoa042176.

42. Grill, J., Sainte-Rose, C., Jouvet, A., Gentet, J. C., Lejars, O., Frappaz, D., Doz, F., Rialland, X., Pichon, F., Bertozzi, A. I., Chastagner, P., Couanet, D., Habrand, J. L., Raquin, M. A., le Deley, M. C., Kalifa, C., \& French Society of Paediatric Oncology. (2005). Treatment of medulloblastoma with postoperative chemotherapy alone: An SFOP prospective trial in young children. The Lancet Oncology, 6(8), 573-580. https://doi.org/ 10.1016/s1470-2045(05)70252-7.

43. Geyer, J. R., Sposto, R., Jennings, M., Boyett, J. M., Axtell, R. A., Breiger, D., et al. (2005). Multiagent chemotherapy and deferred radiotherapy in infants with malignant brain tumors: A report from the Children's Cancer Group. Journal of Clinical Oncology, 23(30), 7621-7631. https://doi.org/10.1200/jco.2005.09.095.

44. Rutkowski, S., Gerber, N. U., von Hoff, K., Gnekow, A., Bode, U., Graf, N., Berthold, F., Henze, G., Wolff, J. E., Warmuth-Metz, M., Soerensen, N., Emser, A., Ottensmeier, H., Deinlein, F., Schlegel, P. G., Kortmann, R. D., Pietsch, T., Kuehl, J., \& German Pediatric Brain Tumor Study Group. (2009). Treatment of early childhood medulloblastoma by postoperative chemotherapy and deferred radiotherapy. Neuro-Oncology, 11(2), 201-210. https://doi.org/10.1215/15228517-2008-084.

45. Cosman, R., Brown, C. S., DeBraganca, K. C., \& Khasraw, M. (2014). Patterns of care in adult medulloblastoma: Results of an international online survey. Journal of Neuro-Oncology, 120(1), 125-129. https://doi.org/10.1007/s11060-014-1525-z.

46. Lassaletta, A., \& Ramaswamy, V. (2016). Medulloblastoma in adults: they're not just big kids. Neuro-Oncology, 18(7), 895897. https://doi.org/10.1093/neuonc/now110.

47. Thompson, M. C., Fuller, C., Hogg, T. L., Dalton, J., Finkelstein, D., Lau, C. C., et al. (2006). Genomics identifies medulloblastoma subgroups that are enriched for specific genetic alterations. Journal of Clinical Oncology, 24(12), 1924-1931. https://doi. org/10.1200/jco.2005.04.4974.

48. Kool, M., Koster, J., Bunt, J., Hasselt, N. E., Lakeman, A., van Sluis, P., Troost, D., Meeteren, N. S., Caron, H. N., Cloos, J., Mrsić, A., Ylstra, B., Grajkowska, W., Hartmann, W., Pietsch, T., Ellison, D., Clifford, S. C., \& Versteeg, R. (2008). Integrated genomics identifies five medulloblastoma subtypes with distinct genetic profiles, pathway signatures and clinicopathological features. PLoS One, 3(8), e3088. https://doi.org/10.1371/journal. pone. 0003088 .

49. Cho, Y. J., Tsherniak, A., Tamayo, P., Santagata, S., Ligon, A., Greulich, H., Berhoukim, R., Amani, V., Goumnerova, L., Eberhart, C. G., Lau, C. C., Olson, J. M., Gilbertson, R. J., Gajjar, A., Delattre, O., Kool, M., Ligon, K., Meyerson, M., Mesirov, J. P., \& Pomeroy, S. L. (2011). Integrative genomic analysis of medulloblastoma identifies a molecular subgroup that drives poor clinical outcome. Journal of Clinical Oncology, 29(11), 1424-1430. https://doi.org/10.1200/jco.2010.28.5148.

50. Parsons, D. W., Li, M., Zhang, X., Jones, S., Leary, R. J., Lin, J. C., Boca, S. M., Carter, H., Samayoa, J., Bettegowda, C., Gallia, G. L., Jallo, G. I., Binder, Z. A., Nikolsky, Y., Hartigan, J., Smith, D. R., Gerhard, D. S., Fults, D. W., VandenBerg, S., Berger, M. S., Marie, S. K., Shinjo, S. M., Clara, C., Phillips, P. C., Minturn, J. E., Biegel, J. A., Judkins, A. R., Resnick, A. C., Storm, P. B., Curran, T., He, Y., Rasheed, B. A., Friedman, H. S., Keir, S. T., McLendon, R., Northcott, P. A., Taylor, M. D., Burger, P. C.,
Riggins, G. J., Karchin, R., Parmigiani, G., Bigner, D. D., Yan, H., Papadopoulos, N., Vogelstein, B., Kinzler, K. W., \& Velculescu, V. E. (2011). The genetic landscape of the childhood cancer medulloblastoma. Science, 331(6016), 435-439. https:// doi.org/10.1126/science.1198056.

51. Ramaswamy, V., Remke, M., Adamski, J., Bartels, U., Tabori, U., Wang, X., Huang, A., Hawkins, C., Mabbott, D., Laperriere, N., Taylor, M. D., \& Bouffet, E. (2016). Medulloblastoma subgroupspecific outcomes in irradiated children: Who are the true highrisk patients? Neuro-Oncology, 18(2), 291-297. https://doi.org/10. 1093/neuonc/nou357.

52. Kool, M., Korshunov, A., Remke, M., Jones, D. T., Schlanstein, M., Northcott, P. A., Cho, Y. J., Koster, J., Schouten-van Meeteren, A., van Vuurden, D., Clifford, S. C., Pietsch, T., von Bueren, A., Rutkowski, S., McCabe, M., Collins, V. P., Bäcklund, M. L., Haberler, C., Bourdeaut, F., Delattre, O., Doz, F., Ellison, D. W., Gilbertson, R. J., Pomeroy, S. L., Taylor, M. D., Lichter, P., \& Pfister, S. M. (2012). Molecular subgroups of medulloblastoma: An international meta-analysis of transcriptome, genetic aberrations, and clinical data of WNT, SHH, Group 3, and Group 4 medulloblastomas. Acta Neuropathologica, 123(4), 473-484. https://doi.org/10.1007/s00401-012-0958-8.

53. Ellison, D. W., Kocak, M., Dalton, J., Megahed, H., Lusher, M. E., Ryan, S. L., et al. (2011). Definition of disease-risk stratification groups in childhood medulloblastoma using combined clinical, pathologic, and molecular variables. Journal of Clinical Oncology, 29(11), 1400-1407. https://doi.org/10.1200/jco.2010. 30.2810 .

54. Ellison, D. W., Dalton, J., Kocak, M., Nicholson, S. L., Fraga, C., Neale, G., Kenney, A. M., Brat, D. J., Perry, A., Yong, W. H., Taylor, R. E., Bailey, S., Clifford, S. C., \& Gilbertson, R. J. (2011). Medulloblastoma: Clinicopathological correlates of SHH, WNT, and non-SHH/WNT molecular subgroups. Acta Neuropathologica, 121(3), 381-396. https://doi.org/10.1007/ s00401-011-0800-8.

55. Ellison, D. W., Onilude, O. E., Lindsey, J. C., Lusher, M. E., Weston, C. L., Taylor, R. E., et al. (2005). Beta-catenin status predicts a favorable outcome in childhood medulloblastoma: The United Kingdom Children's Cancer Study Group Brain Tumour Committee. Journal of Clinical Oncology, 23(31), 7951-7957. https://doi.org/10.1200/jco.2005.01.5479.

56. Clifford, S. C., Lannering, B., Schwalbe, E. C., Hicks, D., O'Toole, K., Nicholson, S. L., et al. (2015). Biomarker-driven stratification of disease-risk in non-metastatic medulloblastoma: Results from the multi-center HIT-SIOP-PNET4 clinical trial. Oncotarget, 6(36), 38827-38839. https://doi.org/10.18632/ oncotarget.5149.

57. Remke, M., Hielscher, T., Northcott, P. A., Witt, H., Ryzhova, M., Wittmann, A., Benner, A., von Deimling, A., Scheurlen, W., Perry, A., Croul, S., Kulozik, A. E., Lichter, P., Taylor, M. D., Pfister, S. M., \& Korshunov, A. (2011). Adult medulloblastoma comprises three major molecular variants. Journal of Clinical Oncology, 29(19), 2717-2723. https://doi.org/10.1200/jco.2011.34.9373.

58. Zhao, F., Ohgaki, H., Xu, L., Giangaspero, F., Li, C., Li, P., Yang, Z., Wang, B., Wang, X., Wang, Z., Ai, L., Zhang, J., Luo, L., \& Liu, P. (2016). Molecular subgroups of adult medulloblastoma: A long-term single-institution study. Neuro-Oncology, 18(7), 982990. https://doi.org/10.1093/neuonc/now050.

59. Cavalli, F. M. G., Remke, M., Rampasek, L., Peacock, J., Shih, D. J. H., Luu, B., et al. (2017). Intertumoral heterogeneity within Medulloblastoma Subgroups. Cancer Cell, 31(6), 737-754.e736. https://doi.org/10.1016/j.ccell.2017.05.005.

60. Robinson, G., Parker, M., Kranenburg, T. A., Lu, C., Chen, X., Ding, L., Phoenix, T. N., Hedlund, E., Wei, L., Zhu, X., Chalhoub, N., Baker, S. J., Huether, R., Kriwacki, R., Curley, N., Thiruvenkatam, R., Wang, J., Wu, G., Rusch, M., Hong, X., 
Becksfort, J., Gupta, P., Ma, J., Easton, J., Vadodaria, B., OnarThomas, A., Lin, T., Li, S., Pounds, S., Paugh, S., Zhao, D., Kawauchi, D., Roussel, M. F., Finkelstein, D., Ellison, D. W., Lau, C. C., Bouffet, E., Hassall, T., Gururangan, S., Cohn, R., Fulton, R. S., Fulton, L. L., Dooling, D. J., Ochoa, K., Gajjar, A., Mardis, E. R., Wilson, R. K., Downing, J. R., Zhang, J., \& Gilbertson, R. J. (2012). Novel mutations target distinct subgroups of medulloblastoma. Nature, 488(7409), 43-48. https://doi.org/ 10.1038/nature11213.

61. Pugh, T. J., Weeraratne, S. D., Archer, T. C., Pomeranz Krummel, D. A., Auclair, D., Bochicchio, J., et al. (2012). Medulloblastoma exome sequencing uncovers subtype-specific somatic mutations. Nature, 488(7409), 106-110. https://doi.org/10.1038/nature11329 http://www.nature.com/nature/journal/v488/n7409/abs/ nature11329.html\#supplementary-information.

62. Northcott, P. A., Shih, D. J., Peacock, J., Garzia, L., Morrissy, A. S., Zichner, T., Stütz, A. M., Korshunov, A., Reimand, J., Schumacher, S. E., Beroukhim, R., Ellison, D. W., Marshall, C. R., Lionel, A. C., Mack, S., Dubuc, A., Yao, Y., Ramaswamy, V., Luu, B., Rolider, A., Cavalli, F. M., Wang, X., Remke, M., Wu, X., Chiu, R. Y., Chu, A., Chuah, E., Corbett, R. D., Hoad, G. R., Jackman, S. D., Li, Y., Lo, A., Mungall, K. L., Nip, K. M., Qian, J. Q., Raymond, A. G., Thiessen, N. T., Varhol, R. J., Birol, I., Moore, R. A., Mungall, A. J., Holt, R., Kawauchi, D., Roussel, M. F., Kool, M., Jones, D. T., Witt, H., Fernandez-L, A., Kenney, A. M., Wechsler-Reya, R. J., Dirks, P., Aviv, T., Grajkowska, W. A., Perek-Polnik, M., Haberler, C. C., Delattre, O., Reynaud, S. S., Doz, F. F., Pernet-Fattet, S. S., Cho, B. K., Kim, S. K., Wang, K. C., Scheurlen, W., Eberhart, C. G., Fèvre-Montange, M., Jouvet, A., Pollack, I. F., Fan, X., Muraszko, K. M., Gillespie, G. Y., di Rocco, C., Massimi, L., Michiels, E. M., Kloosterhof, N. K., French, P. J., Kros, J. M., Olson, J. M., Ellenbogen, R. G., Zitterbart, K., Kren, L., Thompson, R. C., Cooper, M. K., Lach, B., McLendon, R., Bigner, D. D., Fontebasso, A., Albrecht, S., Jabado, N., Lindsey, J. C., Bailey, S., Gupta, N., Weiss, W. A., Bognár, L., Klekner, A., van Meter, T., Kumabe, T., Tominaga, T., Elbabaa, S. K., Leonard, J. R., Rubin, J. B., Liau, L. M., van Meir, E., Fouladi, M., Nakamura, H., Cinalli, G., Garami, M., Hauser, P., Saad, A. G., Iolascon, A., Jung, S., Carlotti, C. G., Vibhakar, R., Ra, Y. S., Robinson, S., Zollo, M., Faria, C. C., Chan, J. A., Levy, M. L., Sorensen, P. H., Meyerson, M., Pomeroy, S. L., Cho, Y. J., Bader, G. D., Tabori, U., Hawkins, C. E., Bouffet, E., Scherer, S. W., Rutka, J. T., Malkin, D., Clifford, S. C., Jones, S. J., Korbel, J. O., Pfister, S. M., Marra, M. A., \& Taylor, M. D. (2012). Subgroup-specific structural variation across 1,000 medulloblastoma genomes. Nature, 488(7409), 49-56. https://doi.org/10. 1038/nature 11327.

63. Schroder, M. (2010). Human DEAD-box protein 3 has multiple functions in gene regulation and cell cycle control and is a prime target for viral manipulation. Biochemical Pharmacology, 79(3), 297-306. https://doi.org/10.1016/j.bcp.2009.08.032.

64. Dunford, A., Weinstock, D. M., Savova, V., Schumacher, S. E., Cleary, J. P., Yoda, A., et al. (2017). Tumor-suppressor genes that escape from X-inactivation contribute to cancer sex bias. Nature Genetics, 49(1), 10-16. https://doi.org/10.1038/ng.3726.

65. Zhukova, N., Ramaswamy, V., Remke, M., Pfaff, E., Shih, D. J., Martin, D. C., Castelo-Branco, P., Baskin, B., Ray, P. N., Bouffet, E., von Bueren, A., Jones, D. T., Northcott, P. A., Kool, M., Sturm, D., Pugh, T. J., Pomeroy, S. L., Cho, Y. J., Pietsch, T., Gessi, M., Rutkowski, S., Bognar, L., Klekner, A., Cho, B. K., Kim, S. K., Wang, K. C., Eberhart, C. G., Fevre-Montange, M., Fouladi, M., French, P. J., Kros, M., Grajkowska, W. A., Gupta, N., Weiss, W. A., Hauser, P., Jabado, N., Jouvet, A., Jung, S., Kumabe, T., Lach, B., Leonard, J. R., Rubin, J. B., Liau, L. M., Massimi, L., Pollack, I. F., Shin Ra, Y., van Meir, E., Zitterbart, K., Schüller, U., Hill, R. M., Lindsey, J. C., Schwalbe, E. C., Bailey, S., Ellison, D. W.,
Hawkins, C., Malkin, D., Clifford, S. C., Korshunov, A., Pfister, S., Taylor, M. D., \& Tabori, U. (2013). Subgroup-specific prognostic implications of TP53 mutation in medulloblastoma. Journal of Clinical Oncology, 31(23), 2927-2935. https://doi. org/10.1200/jco.2012.48.5052.

66. Trubicka, J., Szperl, M., Grajkowska, W., KarkucinskaWieckowska, A., Tarasinska, M., Falana, K., et al. (2016). Identification of a novel inherited ALK variant M1199L in the WNT type of medulloblastoma. Folia Neuropathologica, 54(1), 23-30.

67. Northcott, P. A., Hielscher, T., Dubuc, A., Mack, S., Shih, D., Remke, M., al-Halabi, H., Albrecht, S., Jabado, N., Eberhart, C. G., Grajkowska, W., Weiss, W. A., Clifford, S. C., Bouffet, E., Rutka, J. T., Korshunov, A., Pfister, S., \& Taylor, M. D. (2011). Pediatric and adult sonic hedgehog medulloblastomas are clinically and molecularly distinct. Acta Neuropathologica, 122(2), 231240. https://doi.org/10.1007/s00401-011-0846-7.

68. Kool, M., Jones, D. T., Jager, N., Northcott, P. A., Pugh, T. J., Hovestadt, V., et al. (2014). Genome sequencing of SHH medulloblastoma predicts genotype-related response to smoothened inhibition. Cancer Cell, 25(3), 393-405. https://doi.org/10.1016/j. ccr.2014.02.004

69. Leary, S. E., Zhou, T., Holmes, E., Geyer, J. R., \& Miller, D. C. (2011). Histology predicts a favorable outcome in young children with desmoplastic medulloblastoma: A report from the children's oncology group. Cancer, 117(14), 3262-3267. https://doi.org/10. 1002/cncr.25856.

70. Rutkowski, S., von Hoff, K., Emser, A., Zwiener, I., Pietsch, T., Figarella-Branger, D., et al. (2010). Survival and prognostic factors of early childhood medulloblastoma: An international metaanalysis. Journal of Clinical Oncology, 28(33), 4961-4968. https://doi.org/10.1200/jco.2010.30.2299.

71. Waszak, S. M., Northcott, P. A., Buchhalter, I., Robinson, G. W., Sutter, C., Groebner, S., et al. (2018). Spectrum and prevalence of genetic predisposition in medulloblastoma: A retrospective genetic study and prospective validation in a clinical trial cohort. The Lancet Oncology, 19(6), 785-798. https://doi.org/10.1016/s14702045(18)30242-0.

72. Jones, D. T., Jager, N., Kool, M., Zichner, T., Hutter, B., Sultan, M., et al. (2012). Dissecting the genomic complexity underlying medulloblastoma. Nature, 488(7409), 100-105. https://doi.org/ 10.1038/nature11284.

73. Tchelebi, L., Ashamalla, H., \& Graves, P. R. (2014). Mutant p53 and the response to chemotherapy and radiation. Sub-Cellular Biochemistry, 85, 133-159. https://doi.org/10.1007/978-94-0179211-0 8.

74. Smith, M. J., Beetz, C., Williams, S. G., Bhaskar, S. S., O'Sullivan, J., Anderson, B., et al. (2014). Germline mutations in SUFU cause Gorlin syndrome-associated childhood medulloblastoma and redefine the risk associated with PTCH1 mutations. Journal of Clinical Oncology, 32(36), 4155-4161. https://doi.org/10.1200/ jco.2014.58.2569.

75. Thalakoti, S., \& Geller, T. (2015). Basal cell nevus syndrome or Gorlin syndrome. Handbook of Clinical Neurology, 132, 119 128. https://doi.org/10.1016/b978-0-444-62702-5.00008-1.

76. Remke, M., Ramaswamy, V., Peacock, J., Shih, D. J. H., Koelsche, C., Northcott, P. A., et al. (2013). TERT promoter mutations are highly recurrent in SHH subgroup medulloblastoma. Acta Neuropathologica, 126(6), 917-929. https://doi.org/10. 1007/s00401-013-1198-2.

77. Menyhart, O., \& Gyorffy, B. (2019). Principles of tumorigenesis and emerging molecular drivers of $\mathrm{SHH}$-activated medulloblastomas. Annals of Clinical Translational Neurology, 6(5), 990-1005. https://doi.org/10.1002/acn3.762.

78. Schwalbe, E. C., Williamson, D., Lindsey, J. C., Hamilton, D., Ryan, S. L., Megahed, H., Garami, M., Hauser, P., Dembowska- 
Baginska, B., Perek, D., Northcott, P. A., Taylor, M. D., Taylor, R. E., Ellison, D. W., Bailey, S., \& Clifford, S. C. (2013). DNA methylation profiling of medulloblastoma allows robust subclassification and improved outcome prediction using formalin-fixed biopsies. Acta Neuropathologica, 125(3), 359-371. https://doi. org/10.1007/s00401-012-1077-2.

79. Tamayo, P., Cho, Y. J., Tsherniak, A., Greulich, H., Ambrogio, L., Schouten-van Meeteren, N., et al. (2011). Predicting relapse in patients with medulloblastoma by integrating evidence from clinical and genomic features. Journal of Clinical Oncology, 29(11), 1415-1423. https://doi.org/10.1200/jco.2010.28.1675.

80. Grotzer, M. A., Hogarty, M. D., Janss, A. J., Liu, X., Zhao, H., Eggert, A., Sutton, L. N., Rorke, L. B., Brodeur, G. M., \& Phillips, P. C. (2001). MYC messenger RNA expression predicts survival outcome in childhood primitive neuroectodermal tumor/medulloblastoma. Clinical Cancer Research, 7(8), 2425-2433.

81. Menyhárt, O., Giangaspero, F., \& Győrffy, B. (2019). Molecular markers and potential therapeutic targets in non-WNT/non-SHH (group 3 and group 4) medulloblastomas. Journal of Hematology \& Oncology, 12(1), 29. https://doi.org/10.1186/s13045-019-0712$\mathrm{y}$.

82. Remke, M., Hielscher, T., Korshunov, A., Northcott, P. A., Bender, S., Kool, M., Westermann, F., Benner, A., Cin, H., Ryzhova, M., Sturm, D., Witt, H., Haag, D., Toedt, G., Wittmann, A., Schöttler, A., von Bueren, A., von Deimling, A., Rutkowski, S., Scheurlen, W., Kulozik, A. E., Taylor, M. D., Lichter, P., \& Pfister, S. M. (2011). FSTL5 is a marker of poor prognosis in non-WNT/non-SHH medulloblastoma. Journal of Clinical Oncology, 29(29), 3852-3861. https://doi.org/10.1200/ jco.2011.36.2798.

83. Phoenix, T. N., Patmore, D. M., Boop, S., Boulos, N., Jacus, M. O., Patel, Y. T., Roussel, M. F., Finkelstein, D., Goumnerova, L., Perreault, S., Wadhwa, E., Cho, Y. J., Stewart, C. F., \& Gilbertson, R. J. (2016). Medulloblastoma genotype dictates blood brain barrier phenotype. Cancer Cell, 29(4), 508-522. https://doi.org/10. 1016/j.ccell.2016.03.002.

84. Houschyar, K. S., Tapking, C., Borrelli, M. R., Popp, D., Duscher, D., Maan, Z. N., et al. (2019). Wnt pathway in bone repair and regeneration - what do we know so far. Frontiers in Cell and Developmental Biology, 6, 170-170. https://doi.org/10.3389/ fcell.2018.00170.

85. Svard, J., Heby-Henricson, K., Persson-Lek, M., Rozell, B., Lauth, M., Bergstrom, A., et al. (2006). Genetic elimination of suppressor of fused reveals an essential repressor function in the mammalian hedgehog signaling pathway. Developmental Cell, 10(2), 187-197. https://doi.org/10.1016/j.devcel.2005.12.013.

86. Rudin, C. M., Hann, C. L., Laterra, J., Yauch, R. L., Callahan, C. A., Fu, L., Holcomb, T., Stinson, J., Gould, S. E., Coleman, B., LoRusso, P., von Hoff, D., de Sauvage, F. J., \& Low, J. A. (2009). Treatment of medulloblastoma with hedgehog pathway inhibitor GDC-0449. The New England Journal of Medicine, 361(12), 1173-1178. https://doi.org/10.1056/NEJMoa0902903.

87. Robinson, G. W., Orr, B. A., Wu, G., Gururangan, S., Lin, T., Qaddoumi, I., Packer, R. J., Goldman, S., Prados, M. D., Desjardins, A., Chintagumpala, M., Takebe, N., Kaste, S. C., Rusch, M., Allen, S. J., Onar-Thomas, A., Stewart, C. F., Fouladi, M., Boyett, J. M., Gilbertson, R. J., Curran, T., Ellison, D. W., \& Gajjar, A. (2015). Vismodegib exerts targeted efficacy against recurrent sonic hedgehog-subgroup Medulloblastoma: Results from phase II pediatric brain tumor consortium studies PBTC-025B and PBTC-032. Journal of Clinical Oncology, 33(24), 2646-2654. https://doi.org/10.1200/jco.2014.60.1591.

88. Robinson, G. W., Kaste, S. C., Chemaitilly, W., Bowers, D. C., Laughton, S., Smith, A., et al. (2017). Irreversible growth plate fusions in children with medulloblastoma treated with a targeted hedgehog pathway inhibitor. Oncotarget, 8(41), 69295-69302. https://doi.org/10.18632/oncotarget.20619.

89. Pizer, B. L., \& Clifford, S. C. (2009). The potential impact of tumour biology on improved clinical practice for medulloblastoma: Progress towards biologically driven clinical trials. British Journal of Neurosurgery, 23(4), 364-375. https://doi.org/10. $1080 / 02688690903121807$.

90. Gajjar, A., \& Pizer, B. (2010). Role of high-dose chemotherapy for recurrent medulloblastoma and other CNS primitive neuroectodermal tumors. Pediatric Blood \& Cancer, 54(4), 649651. https://doi.org/10.1002/pbc.22378.

91. Sabel, M., Fleischhack, G., Tippelt, S., Gustafsson, G., Doz, F., Kortmann, R., Massimino, M., Navajas, A., von Hoff, K., Rutkowski, S., Warmuth-Metz, M., Clifford, S. C., Pietsch, T., Pizer, B., Lannering, B., \& SIOP-E Brain Tumour Group. (2016). Relapse patterns and outcome after relapse in standard risk medulloblastoma: A report from the HIT-SIOP-PNET4 study. Journal of Neuro-Oncology, 129(3), 515-524. https://doi.org/10. 1007/s11060-016-2202-1.

92. Ramaswamy, V., Remke, M., Bouffet, E., Faria, C. C., Perreault, S., Cho, Y. J., Shih, D. J., Luu, B., Dubuc, A. M., Northcott, P. A., Schüller, U., Gururangan, S., McLendon, R., Bigner, D., Fouladi, M., Ligon, K. L., Pomeroy, S. L., Dunn, S., Triscott, J., Jabado, N., Fontebasso, A., Jones, D. T., Kool, M., Karajannis, M. A., Gardner, S. L., Zagzag, D., Nunes, S., Pimentel, J., Mora, J., Lipp, E., Walter, A. W., Ryzhova, M., Zheludkova, O., Kumirova, E., Alshami, J., Croul, S. E., Rutka, J. T., Hawkins, C., Tabori, U., Codispoti, K. E., Packer, R. J., Pfister, S. M., Korshunov, A., \& Taylor, M. D. (2013). Recurrence patterns across medulloblastoma subgroups: An integrated clinical and molecular analysis. The Lancet Oncology, 14(12), 1200-1207. https://doi.org/10.1016/s1470-2045(13)70449-2.

93. Wang, X., Dubuc, A. M., Ramaswamy, V., Mack, S., Gendoo, D. M., Remke, M., Wu, X., Garzia, L., Luu, B., Cavalli, F., Peacock, J., López, B., Skowron, P., Zagzag, D., Lyden, D., Hoffman, C., Cho, Y. J., Eberhart, C., MacDonald, T., Li, X. N., van Meter, T., Northcott, P. A., Haibe-Kains, B., Hawkins, C., Rutka, J. T., Bouffet, E., Pfister, S. M., Korshunov, A., \& Taylor, M. D. (2015). Medulloblastoma subgroups remain stable across primary and metastatic compartments. Acta Neuropathologica, 129(3), 449-457. https://doi.org/10.1007/s00401-015-1389-0.

94. Morrissy, A. S., Garzia, L., Shih, D. J., Zuyderduyn, S., Huang, X., Skowron, P., Remke, M., Cavalli, F. M., Ramaswamy, V., Lindsay, P. E., Jelveh, S., Donovan, L. K., Wang, X., Luu, B., Zayne, K., Li, Y., Mayoh, C., Thiessen, N., Mercier, E., Mungall, K. L., Ma, Y., Tse, K., Zeng, T., Shumansky, K., Roth, A. J., Shah, S., Farooq, H., Kijima, N., Holgado, B. L., Lee, J. J., Matan-Lithwick, S., Liu, J., Mack, S. C., Manno, A., Michealraj, K. A., Nor, C., Peacock, J., Qin, L., Reimand, J., Rolider, A., Thompson, Y. Y., Wu, X., Pugh, T., Ally, A., Bilenky, M., Butterfield, Y. S., Carlsen, R., Cheng, Y., Chuah, E., Corbett, R. D., Dhalla, N., He, A., Lee, D., Li, H. I., Long, W., Mayo, M., Plettner, P., Qian, J. Q., Schein, J. E., Tam, A., Wong, T., Birol, I., Zhao, Y., Faria, C. C., Pimentel, J., Nunes, S., Shalaby, T., Grotzer, M., Pollack, I. F., Hamilton, R. L., Li, X. N., Bendel, A. E., Fults, D. W., Walter, A. W., Kumabe, T., Tominaga, T., Collins, V. P., Cho, Y. J., Hoffman, C., Lyden, D., Wisoff, J. H., Garvin JH Jr, Stearns, D. S., Massimi, L., Schüller, U., Sterba, J., Zitterbart, K., Puget, S., Ayrault, O., Dunn, S. E., Tirapelli, D. P., Carlotti, C. G., Wheeler, H., Hallahan, A. R., Ingram, W., MacDonald, T., Olson, J. J., van Meir, E., Lee, J. Y., Wang, K. C., Kim, S. K., Cho, B. K., Pietsch, T., Fleischhack, G., Tippelt, S., Ra, Y. S., Bailey, S., Lindsey, J. C., Clifford, S. C., Eberhart, C. G., Cooper, M. K., Packer, R. J., Massimino, M., Garre, M. L., Bartels, U., Tabori, U., Hawkins, C. E., Dirks, P., Bouffet, E., Rutka, J. T., WechslerReya, R. J., Weiss, W. A., Collier, L. S., Dupuy, A. J., Korshunov, 
A., Jones, D. T., Kool, M., Northcott, P. A., Pfister, S. M., Largaespada, D. A., Mungall, A. J., Moore, R. A., Jabado, N., Bader, G. D., Jones, S. J., Malkin, D., Marra, M. A., \& Taylor, M. D. (2016). Divergent clonal selection dominates medulloblastoma at recurrence. Nature, 529(7586), 351-357. https://doi.org/ 10.1038/nature16478.

95. Hill, R. M., Kuijper, S., Lindsey, J. C., Petrie, K., Schwalbe, E. C., Barker, K., Boult, J. K., Williamson, D., Ahmad, Z., Hallsworth, A., Ryan, S. L., Poon, E., Robinson, S. P., Ruddle, R., Raynaud, F. I., Howell, L., Kwok, C., Joshi, A., Nicholson, S. L., Crosier, S., Ellison, D. W., Wharton, S. B., Robson, K., Michalski, A., Hargrave, D., Jacques, T. S., Pizer, B., Bailey, S., Swartling, F. J., Weiss, W. A., Chesler, L., \& Clifford, S. C. (2015). Combined MYC and P53 defects emerge at medulloblastoma relapse and define rapidly progressive, therapeutically targetable disease. Cancer Cell, 27(1), 72-84. https://doi.org/10.1016/j.ccell.2014. 11.002.

96. Wu, X., Northcott, P. A., Dubuc, A., Dupuy, A. J., Shih, D. J., Witt, H., Croul, S., Bouffet, E., Fults, D. W., Eberhart, C. G., Garzia, L., van Meter, T., Zagzag, D., Jabado, N., Schwartzentruber, J., Majewski, J., Scheetz, T. E., Pfister, S. M., Korshunov, A., Li, X. N., Scherer, S. W., Cho, Y. J., Akagi, K., MacDonald, T., Koster, J., McCabe, M., Sarver, A. L., Collins, V. P., Weiss, W. A., Largaespada, D. A., Collier, L. S., \& Taylor, M. D. (2012). Clonal selection drives genetic divergence of metastatic medulloblastoma. Nature, 482(7386), 529-533. https://doi.org/ 10.1038 /nature 10825 .

97. Pardoll, D. M. (2012). The blockade of immune checkpoints in cancer immunotherapy. Nature Reviews. Cancer, 12(4), 252-264. https://doi.org/10.1038/nrc3239.

98. Hodi, F. S., O'Day, S. J., McDermott, D. F., Weber, R. W., Sosman, J. A., Haanen, J. B., et al. (2010). Improved survival with ipilimumab in patients with metastatic melanoma. The New England Journal of Medicine, 363(8), 711-723. https://doi.org/ 10.1056/NEJMoa1003466.

99. Motzer, R. J., Escudier, B., McDermott, D. F., George, S., Hammers, H. J., Srinivas, S., et al. (2015). Nivolumab versus everolimus in advanced renal-cell carcinoma. New England Journal of Medicine, 373(19), 1803-1813. https://doi.org/10. 1056/NEJMoa1510665.

100. Blumenthal, D. T., Yalon, M., Vainer, G. W., Lossos, A., Yust, S., Tzach, L., Cagnano, E., Limon, D., \& Bokstein, F. (2016). Pembrolizumab: First experience with recurrent primary central nervous system (CNS) tumors. Journal of Neuro-Oncology, 129(3), 453-460. https://doi.org/10.1007/s11060-016-2190-1.

101. Kurz, S. C., Cabrera, L. P., Hastie, D., Huang, R., Unadkat, P., Rinne, M., Nayak, L., Lee, E. Q., Reardon, D. A., \& Wen, P. Y. (2018). PD-1 inhibition has only limited clinical benefit in patients with recurrent high-grade glioma. Neurology, 91(14), e1355e1359. https://doi.org/10.1212/wnl.0000000000006283.

102. Gorsi, H. S., Malicki, D. M., Barsan, V., Tumblin, M., Yeh-Nayre, L., Milburn, M., et al. (2019). Nivolumab in the treatment of recurrent or refractory pediatric brain tumors: A single institutional experience. Journal of Pediatric Hematology/Oncology, 41(4), e235-e241. https://doi.org/10.1097/mph.0000000000001339.

103. Merchant, M. S., Wright, M., Baird, K., Wexler, L. H., RodriguezGalindo, C., Bernstein, D., Delbrook, C., Lodish, M., Bishop, R., Wolchok, J. D., Streicher, H., \& Mackall, C. L. (2016). Phase I clinical trial of Ipilimumab in pediatric patients with advanced solid tumors. Clinical Cancer Research, 22(6), 1364-1370. https://doi.org/10.1158/1078-0432.ccr-15-0491.

104. Picarda, E., Ohaegbulam, K. C., \& Zang, X. (2016). Molecular pathways: Targeting B7-H3 (CD276) for human cancer immunotherapy. Clinical Cancer Research, 22(14), 3425-3431. https:// doi.org/10.1158/1078-0432.ccr-15-2428.
105. Vonderheide, R. H. (2007). Prospect of targeting the CD40 pathway for cancer therapy. Clinical Cancer Research, 13(4), 10831088. https://doi.org/10.1158/1078-0432.ccr-06-1893.

106. Moon, Y. W., Hajjar, J., Hwu, P., \& Naing, A. (2015). Targeting the indoleamine 2,3-dioxygenase pathway in cancer. Journal for Immunotherapy of Cancer, 3, 51. https://doi.org/10.1186/s40425015-0094-9.

107. Bilir, C., \& Sarisozen, C. (2017). Indoleamine 2,3-dioxygenase (IDO): Only an enzyme or a checkpoint controller? Journal of Oncological Sciences, 3(2), 52-56. https://doi.org/10.1016/j.jons. 2017.04.001.

108. Kaufman, H. L., Kohlhapp, F. J., \& Zloza, A. (2015). Oncolytic viruses: A new class of immunotherapy drugs. Nature Reviews. Drug Discovery, 14(9), 642-662. https://doi.org/10.1038/ $\operatorname{nrd} 4663$.

109. Varela-Guruceaga, M., Tejada-Solís, S., García-Moure, M., Fueyo, J., Gomez-Manzano, C., Patiño-García, A., et al. (2018). Oncolytic viruses as therapeutic tools for pediatric brain tumors. Cancers, 10(7), 226. https://doi.org/10.3390/cancers10070226.

110. Studebaker, A. W., Hutzen, B. J., Pierson, C. R., Haworth, K. B., Cripe, T. P., Jackson, E. M., \& Leonard, J. R. (2017). Oncolytic herpes virus rRp450 shows efficacy in Orthotopic Xenograft group 3/4 Medulloblastomas and atypical Teratoid/Rhabdoid tumors. Mol Ther Oncolytics, 6, 22-30. https://doi.org/10.1016/j. omto.2017.05.005

111. Friedman, G. K., Moore, B. P., Nan, L., Kelly, V. M., Etminan, T., Langford, C. P., Xu, H., Han, X., Markert, J. M., Beierle, E. A., \& Gillespie, G. Y. (2016). Pediatric medulloblastoma xenografts including molecular subgroup 3 and CD133+ and CD15+ cells are sensitive to killing by oncolytic herpes simplex viruses. NeuroOncology, 18(2), 227-235. https://doi.org/10.1093/neuonc/ nov123.

112. Markert, J. M., Razdan, S. N., Kuo, H. C., Cantor, A., Knoll, A., Karrasch, M., Nabors, L. B., Markiewicz, M., Agee, B. S., Coleman, J. M., Lakeman, A. D., Palmer, C. A., Parker, J. N., Whitley, R. J., Weichselbaum, R. R., Fiveash, J. B., \& Gillespie, G. Y. (2014). A phase 1 trial of oncolytic HSV-1, G207, given in combination with radiation for recurrent GBM demonstrates safety and radiographic responses. Molecular Therapy, 22(5), 10481055. https://doi.org/10.1038/mt.2014.22.

113. Friedman, G. K., Bernstock, J. D., Chen, D., Nan, L., Moore, B. P., Kelly, V. M., Youngblood, S. L., Langford, C. P., Han, X., Ring, E. K., Beierle, E. A., Gillespie, G. Y., \& Markert, J. M. (2018). Enhanced sensitivity of patient-derived pediatric high-grade brain tumor Xenografts to Oncolytic HSV-1 Virotherapy correlates with Nectin-1 expression. Scientific Reports, 8(1), 13930. https://doi. org/10.1038/s41598-018-32353-x.

114. Aref, S., Bailey, K., \& Fielding, A. (2016). Measles to the rescue: A review of oncolytic measles virus. Viruses, 8(10), 294. https:// doi.org/10.3390/v8100294.

115. Gromeier, M., \& Nair, S. K. (2018). Recombinant poliovirus for cancer immunotherapy. Annual Review of Medicine, 69, 289-299. https://doi.org/10.1146/annurev-med-050715-104655.

116. Desjardins, A., Gromeier, M., Herndon, J. E., Beaubier, N., Bolognesi, D. P., Friedman, A. H., et al. (2018). Recurrent glioblastoma treated with recombinant poliovirus. New England Journal of Medicine, 379(2), 150-161. https://doi.org/10.1056/ NEJMoa1716435.

117. Batich, K. A., Reap, E. A., Archer, G. E., Sanchez-Perez, L., Nair, S. K., Schmittling, R. J., Norberg, P., Xie, W., Herndon 2nd, J. E., Healy, P., McLendon, R., Friedman, A. H., Friedman, H. S., Bigner, D., Vlahovic, G., Mitchell, D. A., \& Sampson, J. H. (2017). Long-term survival in glioblastoma with cytomegalovirus pp65-targeted vaccination. Clinical Cancer Research, 23(8), 1898-1909. https://doi.org/10.1158/1078-0432.ccr-16-2057. 
118. Martinez, M., \& Moon, E. K. (2019). CAR T cells for solid tumors: New strategies for finding, infiltrating, and surviving in the tumor microenvironment. Frontiers in Immunology, 10, 128-128. https://doi.org/10.3389/fimmu.2019.00128.

119. Nellan, A., Rota, C., Majzner, R., Lester-McCully, C. M., Griesinger, A. M., Mulcahy Levy, J. M., et al. (2018). Durable regression of medulloblastoma after regional and intravenous delivery of anti-HER2 chimeric antigen receptor T cells. Journal for Immunotherapy of Cancer, 6(1), 30-30. https://doi.org/10.1186/ s40425-018-0340-z.

120. Perez-Martinez, A., Fernandez, L., \& Diaz, M. A. (2016). The therapeutic potential of natural killer cells to target medulloblastoma. Expert Review of Anticancer Therapy, 16(6), 573-576. https:// doi.org/10.1080/14737140.2016.1184978.

121. Castriconi, R., Dondero, A., Negri, F., Bellora, F., Nozza, P., Carnemolla, B., Raso, A., Moretta, L., Moretta, A., \& Bottino, C. (2007). Both CD133+ and CD133- medulloblastoma cell lines express ligands for triggering NK receptors and are susceptible to NK-mediated cytotoxicity. European Journal of Immunology, 37(11), 3190-3196. https://doi.org/10.1002/eji.200737546.

122. Powell, A. B., Yadavilli, S., Saunders, D., Van Pelt, S., Chorvinsky, E., Burga, R. A., et al. (2019). Medulloblastoma rendered susceptible to NK-cell attack by TGF $\beta$ neutralization. Journal of Translational Medicine, 17(1), 321-321. https://doi. org/10.1186/s12967-019-2055-4.

123. Forget, A., Martignetti, L., Puget, S., Calzone, L., Brabetz, S., Picard, D., et al. (2018). Aberrant ERBB4-SRC signaling as a hallmark of group 4 medulloblastoma revealed by integrative phosphoproteomic profiling. Cancer Cell, 34(3), 379-395.e377. https://doi.org/10.1016/j.ccell.2018.08.002.

Publisher's note Springer Nature remains neutral with regard to jurisdictional claims in published maps and institutional affiliations. 